University of Louisville

ThinkIR: The University of Louisville's Institutional Repository

Electronic Theses and Dissertations

$5-2012$

\title{
Land cover classification of active fire and burned area detections for Canadian provinces, 2001-2010.
}

Tyler Kerr

University of Louisville

Follow this and additional works at: https://ir.library.louisville.edu/etd

\section{Recommended Citation}

Kerr, Tyler, "Land cover classification of active fire and burned area detections for Canadian provinces, 2001-2010." (2012). Electronic Theses and Dissertations. Paper 737.

https://doi.org/10.18297/etd/737

This Master's Thesis is brought to you for free and open access by ThinkIR: The University of Louisville's Institutional Repository. It has been accepted for inclusion in Electronic Theses and Dissertations by an authorized administrator of ThinkIR: The University of Louisville's Institutional Repository. This title appears here courtesy of the author, who has retained all other copyrights. For more information, please contact thinkir@louisville.edu. 


\title{
LAND COVER CLASSIFICATION OF ACTIVE FIRE AND BURNED AREA DETECTIONS FOR CANADIAN

\author{
PROVINCES, 2001 - 2010
}

\author{
By \\ Tyler Kerr \\ B.S., University of Louisville, 2010

\begin{abstract}
A Thesis
Submitted to the Faculty of the

College of Arts and Sciences of the University of Louisville

in Partial Fulfillment of the Requirements

for the Degree of
\end{abstract}

Masters of Science

Department of Geography and Geosciences

University of Louisville

Louisville, Kentucky

May 2012 


\title{
LAND COVER CLASSIFICATION OF ACTIVE FIRE AND BURNED AREA DETECTIONS FOR CANADIAN PROVINCES, $2001-2010$
}

\author{
By \\ Tyler Kerr \\ Department of Geography and Geosciences \\ University of Louisville
}

A Master's Thesis Approved

April 13, 2012

By the following faculty mentors:

Keith R. Mountain

Thesis Mentor

David A. Howarth

Second Reader

George Higgins

Third (Outside) Reader 


\section{DEDICATION}

This Thesis is dedicated to my Parents

Jamie and Randy Martin and Terrence Kerr

Who provided me with the educational opportunity to complete this work. 


\section{ACKNOWLEDGEMENTS}

I would like to thank the Chair of my Thesis Committee, Dr. Keith Mountain, for his guidance and patience while stepping into the role of my primary committee member. I would also like to thank my other committee members, Dr. David Howarth and Dr. George Higgins, for their comments and assistance in completing this document. I would also like to express my gratitude to Dr. Jessica McCarty for funding my research and affording me the opportunity to pursue a Masters degree. I would also like to thank my parents, Randy and Jamie Martin and Terry Kerr, for providing me with the opportunity and the confidence to pursue a college education. Lastly, I would like to thank my brother, Lane Martin, for consistently being a good role-model for me to look to for inspiration. 


\section{ABSTRACT \\ LAND COVER CLASSIFICATION OF ACTIVE FIRE AND BURNED AREA DETECTIONS FOR CANADIAN PRVINCES, 2001 - 2010}

Tyler Kerr

May 2012

This thesis is a methodological analysis of fire locations in Canadian provinces from 2001 to 2010 . The research presented in this thesis highlights the dominant fire types for each province. Accurately locating active fires and burned area is critical to improving emissions estimates of greenhouse gases and black carbon in northern latitudes. Black carbon and emissions are climate changers. Continual release of emissions from a source location has been shown to alter the atmosphere near the source. Black carbon, or soot ash, deposited on arctic snow and ice leads to faster deterioration of the snow and ice. Detected fires and burned areas are recorded by the MODIS satellite sensor on-board the geo-synchronous orbiting Terra and Aqua satellite platforms.

The Introduction and Present Study sections introduce the topic. Satellite data and imagery greatly increase accuracy of emissions estimates and aid emergency response teams and hazard monitoring situations. Infrared sensors onboard the Aqua and Terra satellites allow scientists, emergency planners, and citizens to monitor fires that may be hazardous to their lives, property, and families. The MODIS sensor also allows us the unique perspective of spatially locating fires and their areal extent. 
The Data section describes the technological specifications of the three remote sensing products: MODIS Active Fire Product, MODIS Burned Area Product, and MODIS Land Cover Dataset.

The Literature Review section situates this thesis into its historical perspective. Remote sensing is a new science; new techniques are being developed daily. This exciting new science allows researchers to study the specific wavelengths of light that are not visible to the naked eye. The Methodology section justifies the use of the techniques used in this project and presents a past study that was conducted to test the various products available in order to produce the most accurate picture of what is occurring on the ground.

The Results and Conclusions present the spatial and temporal distributions of fires in Canadian Provinces from 2001 to 2010. Emergency response units and researchers can use this research to plan for future fire events. This research is also a first step in producing emissions estimates for the region. 


\section{TABLE OF CONTENTS}

\section{PAGE}

DEDICATION ................................................................. ii

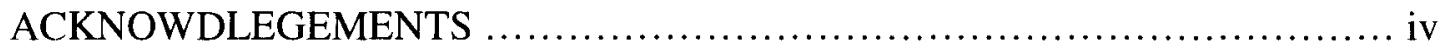

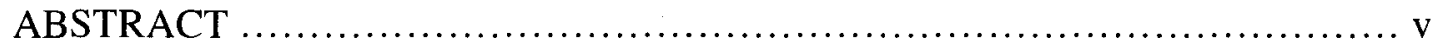

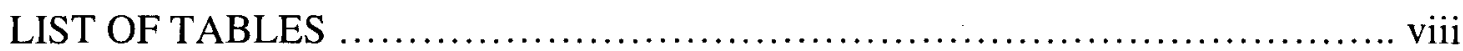

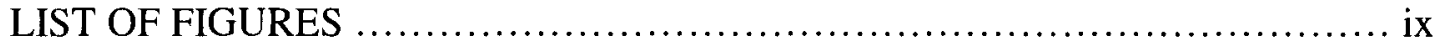

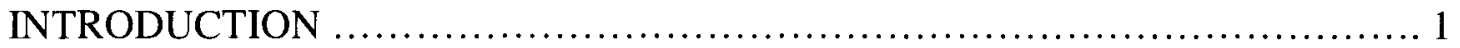

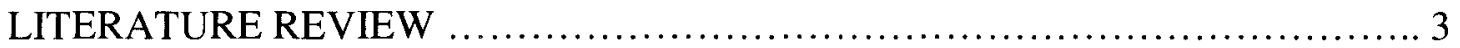

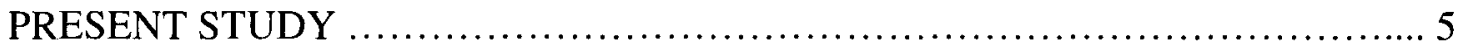

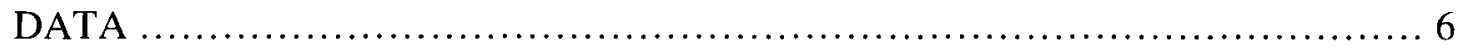

MODIS ACTIVE FIRE PRODUCT (MOD14/MYD14) ....................... 6

MODIS BURNED AREA PRODUCT (MCD45A1) .......................... 6

MODIS 1 KM LAND COVER DATASET (MOD12Q1) ….................. 7

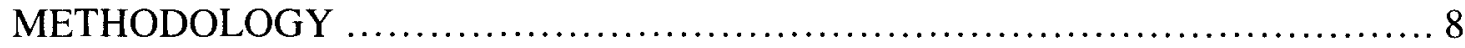

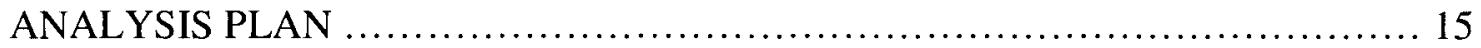

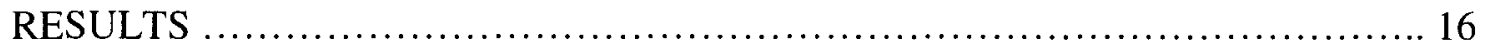

PEACE RIVER AGRICULTURAL AREA FIELD WORK .................... 46

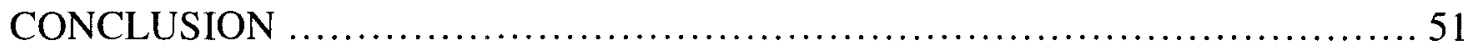




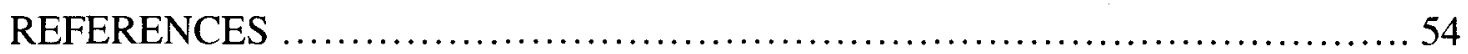

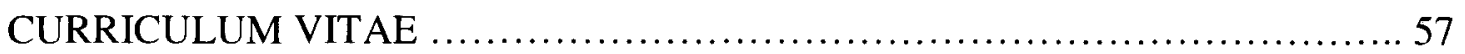




\section{LIST OF TABLES}

TABLE

PAGE

1. Active fires detected in cropland (LC12 and 14) by season: Winter (January-March), spring (April-June), summer (July-September) and fall (October-December) with seasonal high shown in bold

2. Burned area in hectares detected in cropland (LC 12) by season: Winter (JanuaryMarch), spring (April-June), summer (July-September) and fall (October-December) with

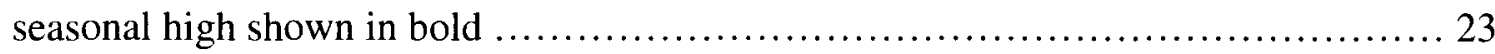

3. Raw number count of AF detections for Alberta from 2001 to 2010 ................ 31

4. Raw number count of AF detections for British Columbia from 2001 to 2010 ....... 33

5. Raw number count of AF detections for Manitoba from 2001 to 2010 ............... 35

6. Raw number count of AF detections for Saskatchewan from 2001 to 2010 ........... 37

7. Raw number count of BA detections for Canada from 2003 to 2010 by season ....... 37

8. Raw number count of BA detections for Alberta from 2003 to 2010 by season ...... 39

9. Raw number count of BA detections for British Columbia from 2003 to 2010 by

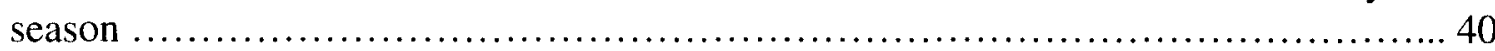

10. Raw number count of BA detections for Manitoba from 2003 to 2010 by season ... 41

11. Raw number count of BA detections for Saskatchewan from 2003 to 2010 by season.

12. Raw number count of BA detections for Quebec from 2003 to 2010 by season .... 43

13. Raw number count of BA detections for Ontario from 2003 to 2010 by season .... 44

14. Raw number count of BA detections for New Brunswick from 2003 to 2010 by season 


\section{LIST OF FIGURES}

FIGURE

PAGE

1. MODIS land cover classes aggregated for active fire classification 9

2. Original MODIS LCP classifications below their respective re-classified land cover

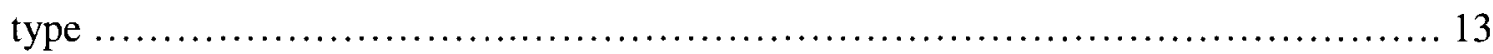

3. Count of MODIS Burned Area Pixels by re-classified land cover type ............. 14

4. Count of GLOBCOVER Burned Area Pixels by re-classified land cover type ....... 14

5. Count of MODIS Burned Area Pixels by re-classified land cover type $\ldots \ldots \ldots \ldots \ldots 14$

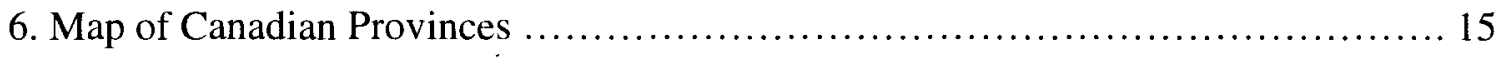

7. Cropland, Forest, and Grassland Active Fire points mapped to show general distribution over Canada ................................................... 16

8. The location of active fires from 2001-10 identified by MODIS land cover type .... 18

9. The average (2001-10) seasonality of the dominant land cover fires: cropland, forest, and shrubland. Seasons are winter (January - March); spring (April - June); summer (July

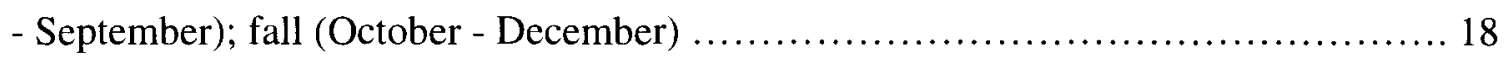

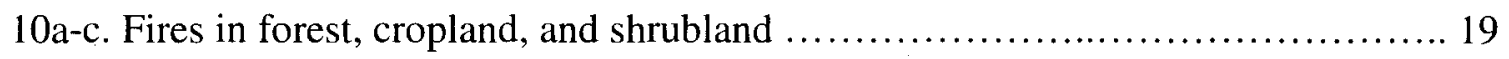

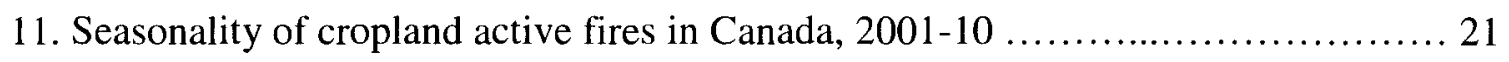

12. Canadian AF points by land cover classification for 2001 to $2010 \ldots \ldots \ldots \ldots \ldots . \ldots 24$

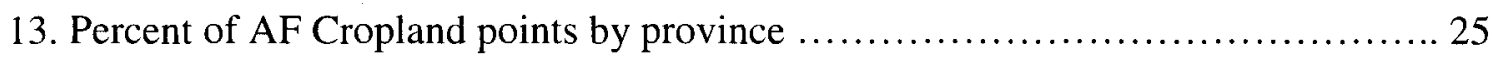

14. Number of AF detections cropland by province from 2001 to 2010 ............... 26

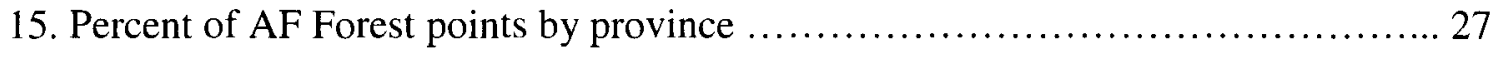

16. Number of AF detections forest by province from 2001 to 2010 ............... 28 
17. Percent of AF Grassland points by province ................................ 29

18. Number of AF detections grassland by province from 2001 to $2010 \ldots \ldots \ldots \ldots \ldots . \ldots . \ldots . \ldots$

19. Number of AF detections by land cover class for Alberta from 2001 to 2010 ...... 31

20. Number of AF detections by land cover class for British Columbia from 2001 to

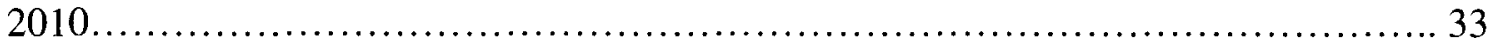

21. Number of AF detections by land cover class for Manitoba from 2001 to 2010 ..... 34

22. Number of AF detections by land cover class for Saskatchewan from 2001 to

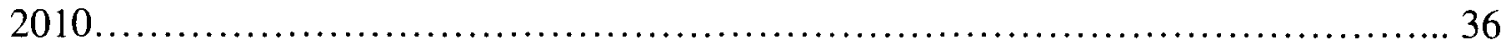

23. Seasonal BA detections from 2003 to 2010 in Alberta ................................. 39

24. Seasonal BA detections from 2003 to 2010 in British Columbia ................... 40

25. Seasonal BA detections from 2003 to 2010 in Manitoba .......................... 41

26. Seasonal BA detections from 2003 to 2010 in Saskatchewan .................... 42

27. Seasonal BA detections from 2003 to 2010 in Quebec .......................... 43

28. Seasonal BA detections from 2003 to 2010 in Ontario ........................... 44

29. Seasonal BA detections from 2003 to 2010 in New Brunswick ................... 45

30. Location of field work GPS points collected and MODIS active fire detections in the Peace River agricultural area .................................................... 46

31. Picture taken at active fire location (field point number 6) with side comparison of field in Google Earth ........................................................... 47

32a-b. Field points 0 and 2 as depicted in Figure 30 (page46) f........................ 48

32c-d. Field points 4 and 5 as depicted in Figure 30 (page 46) ........................ 49

32e-f. Field points 7 and 8 as depicted in Figure 30 (page 46) ........................ 50 


\section{INTRODUCTION}

Fire is a primary disturbance agent in Canadian ecosystems and has significant social, environmental and economic consequences (Van de Werf et al. 2006, E. S. Kasischke et al. 2006, and Soja et al. 2007). Accurate location and identification of open biomass burning, especially in northern latitudes, are critical to understanding the transfer of gases and particles into earth's atmosphere. It is also important as they aid atmospheric models in estimating black carbon (BC) deposition on arctic snow (French et al. 2008, BondLamberty et al. 2007).

$\mathrm{BC}$ deposits alter the surface albedo and affect microclimates due to changes in the local energy balance. Changes over time to local levels of insolation and reflection are important for climate monitoring (Langman et al. 2009, Korontzi et al. 2006). Previous research has shown that remote sensing products can be used to identify active fire locations as well as post-burn scarring in surface vegetation and soil (Soja et al 2009, Korontzi et al 2006, and French et al. 2008).

The purpose of this study is to gain insight into the distribution and occurrence level of agricultural fires, and to set the groundwork for more specific analysis of greenhouse gas estimates for specific crop and tree types in future papers.

This provincial study of Canada utilizes existing remote sensing products to relate active fire locations, burned area and greenhouse gas emission estimations with land cover and/or land use classes for years 2003 to 2010 (Soja et al. 2009). These remote 
sensing products include the Moderate Resolution Imaging Spectroradiometer (MODIS) Active Fire Points (MOD/MYD 14) and the Burned Area Product (MCD45A1),

Several complimentary questions will be addressed during the course of the research project. The first question to be addressed is where and when the most active fires and burned areas being detected are located. Upon completion of the study it will be known in which Canadian provinces the most burned area and active fires occur for each year. Year to year variability is being coupled with an assessment of concurrent meteorological history of the region. Analysis of the data will also show which months produce the most total fire detection. Months will also be grouped into four seasons (winter, spring, summer, and fall) to determine inter-seasonal variability of fire occurrences.

The second question to be addressed is what percentage of detected burning is located in agricultural land. The MODIS Land Cover Product (MODIS LCP) classifies land cover into 21 categories. The 21 original categories are resolute enough to distinguish between deciduous tree types. It is important to determine in which land cover category fires occur throughout the seasons. To acquire this information the 21 MODIS LCP categories are reclassified into seven broad groups (Cropland, Forest, Grassland, Urban area, Water bodies, Wetlands, and Barren soil). The purpose is to highlight agricultural fire and burned area detections. This is important because agricultural fires are human-sourced emissions unlike forest fires which are a mixture of naturally caused and human-caused combustion (French et al 2008). 


\section{LITERATURE REVIEW}

Agricultural fires are important because their role in climate change is understudied compared to Canadian forest fire monitoring and records. Agricultural fires are almost always the product of human activity and are critical in estimating human-source greenhouse gas emissions (Korontzi et al. 2006). Cropland is intentionally burned for two reasons; to clear the field of residue in preparation of planting and to fertilize the soil.

In Canada, regulation of open burning is different per province, but wheat stubble is often removed with fire. Wheat is the most widely grown crop, accounting for an average of 10,000,000 hectares seeded per year (Ag Canada 2011).

It is important to understand that not all 'smoke' is created equally. Smoke and material that is emitted from fires bear the markers of what is actually being burnt. Corn, for example, will not only burn at a different rate of speed than say wheat, but will also release different percentages of chemical compounds such as sulfur dioxide, carbon monoxide, and BC soot ash (Korontzi et al. 2006, McCarty et al. 2010). Various plant species will also produce different percentages of combustion on a scale from 0 to $100 \%$, with $100 \%$ being total combustion and thus no residue or large material left on the ground once the fire ceases to burn. Fire intensity and duration of the burn are also determining factors in whether vegetative material reaches complete combustion, or no large particles besides ash, soot, and small residuals (McCarty et al. 2009). 
The location of fires is also important as it determines the soil composition, vegetation, moisture content, and will also impact the air humidity and temperatures throughout the four seasons. Soil also burns and plays a role in producing BC and other chemical emissions when vegetative layers are burnt (Gerard et al. 2003). Alfisols or soils rich in iron $(\mathrm{Fe})$ and aluminum $(\mathrm{Al})$ dominate the Canadian forest landscape and the hinter regions of the agricultural area of Canada (Ag Canada 2011). When woody biomass is cleared and burned it releases a chemical marker of the alfisols which can be traced from the black carbon depositions in the Arctic (Hegg et al 2010). When soil is burnt it loses amounts of organic material and change occurs to its chemical composition. Burnt alfisols typically see a reduction in Nitrogen $(\mathrm{N})$, Phosphorus (P), and Potassium (K). Soil Ph levels change as well (Mokwunye 2000).

Fire intensity and levels of combustion are also dependent upon the fuel load and fire type. Wooster and Zhang (2004) observed that boreal forest fires burn less intensely in Russia than North America due to differences in dominant fire type. Dense ground pack, shrub, and brush combined with high crown fire capacity in North American forests are responsible for the intensity compared to the more spread out forest structures with less ground clutter seen in Russian forests (Wooster and Zhang 2004).

Northern boreal forests play an important role in the global carbon budget; these forests act as large carbon sinks and accounting for $49 \%$ of the total carbon pool in forested ecosystems (Gerard et al. 2003). From 1997 to 2009 Van der Werf (2010) conducted a study on global emissions. He concluded that the boreal region of North America accounted forest fires to be almost $96 \%$ of the total emissions. However, 
emission estimates in the boreal region had higher uncertainties due to difficulties in estimating fuel consumption in organic soils (Van der Werf 2010).

Increases in global warming are expected to extend the fire season, increasing the likelihood of more frequent large intensity forest fires (Wulder et al. 2009) and extending the season for farmers to perform agricultural residue burning in addition to field expansion/land cover conversion (McCarty et al. 2009). The dominant ecosystem coverage in Canada is shrub, boreal forest, sparse vegetation, other forest and agriculture (Ichoku et al. 2008).

Although Canada is the second-largest country in the world, approximately $90 \%$ of the population is concentrated within $160 \mathrm{~km}$ of the US border (CIA World Factbook 2010). The remoteness of the country has resulted in a limited inventory of agricultural fires and forest composition that makes the incorporation of remote sensing particularly useful in this region.

\section{PRESENT STUDY}

The objective of this thesis is to identify the spatial locations of fires in Canadian provinces. This study also identifies the time of year and the seasonal variances between the occurrences of fires. Lastly this thesis identifies the major land cover classifications that are being affected by fires; for example whether or not British Columbia is experiencing more fires in forests or in agricultural areas. The study covers a time period from 2001 to 2010. 


\section{DATA}

The Moderate Resolution Imaging Spectrometer (MODIS) sensors are carried onboard the sun-synchronous polar orbiting Aqua and Terra satellites, giving them the benefit of covering the earth four times per day for $10+$ years. The multispectral sensor has 36 bands total and was designed in part specifically for fire detection and comprehensive terrestrial monitoring for improved global land cover mapping (Justice et al., 2002; Friedl et al. 2002). Specific products used or this work include:

\section{MODIS Active Fire Product (MOD14/MYD14)}

This research includes active fire detections from MODIS Data Processing System (MODAPS) Collection 5 (version 5.1) for the years 2001-2010 (NASA/University of Maryland 2002). The MODIS Level 2 fire product collects daily hotspot/active fire locations (latitude, longitude) at a $1 \mathrm{~km}$ resolution. Two satellites, MOD14 (Terra) and MYD14 (Aqua), are integrated sun synchronous satellites whose images are stitched together to form resolute images of Earth. The MODIS active-fire algorithm uses the mid-infrared radiation from fires to examine each pixel and subsequently classify it as either missing data, cloud, water, non-fire, fire or unknown (Justice et al. 2006).

\section{MODIS Burned Area Product (MCD45A1)}

The monthly MODIS Burned Area product (MCD45Al) was used for this study over the years 2003-2010 and was provided by the University of Maryland FIRMS in a GEOTIFF 
format (NASA/University of Maryland 2002). The year 2003 was used as the start year instead of 2001 to due improvements to the processing algorithm. MCD45A1 is visualized in a spatial resolution of 500 meters. The MCD45A1 product uses an algorithm trained to detect spectral, temporal and structural changes that characterize burned area by deposits of charcoal and ash, removal of vegetation and alteration of the vegetation structure (Boschetti et al. 2009). Thus the MODIS Burned Area product detects burned pixels, categorizes the intensity of fire and estimates the amount of burned area at a global scale (Giglio et al. 2003; Giglio et al. 2005).

\section{MODIS $1 \mathrm{~km}$ Land Cover dataset (MOD12Q1)}

The MODIS $1 \mathrm{~km}$ Land Cover data (MOD12Q1) product was used to identify the primary land cover where active fire and burned area were detected. The MOD12Q1 product uses a supervised decision-tree classification algorithm to assign land cover classes based on MODIS level 3 products. The primary land cover classification scheme is based on the International Geosphere Biosphere Programme (IGBP) and identifies 17 categories of land cover. 


\section{METHODOLOGY}

In this study zonal statistics and/or raster calculator operations have been carried out on each of the fire identification products to assign Land Cover values to each detected pixel based on the MODIS Land Cover Product (MOD-12) (1000 m) land cover map. The zonal statistics and raster calculator operations classify each detected fire or burned area pixel into a specific land cover category such as "cultivated agricultural land" or "mixed forest." These specific categories will be further generalized and re-categorized for the purpose of highlighting agricultural land and vegetation burning in Canadian provinces. Descriptive statistic, graphs, and thematic mapping are useful to visually show the yearly and seasonal variability of fire detections.

All data processing was performed in a GIS environment using ESRI ArcGIS software versions 9.3.1 and 10. Active fire data points for the years $2001-2010$ were assigned a MODIS land cover classification. The 16 MODIS land cover classes were aggregated into 7 new classifications that broadly reflected the dominant land cover type

(Figure 1). Next, the attribute fields of 'month', 'year', 'season', 'province' and 'reclassified land cover' were added to the dataset. Scan failures by the sensor were identified on 4 dates and removed from analysis. 


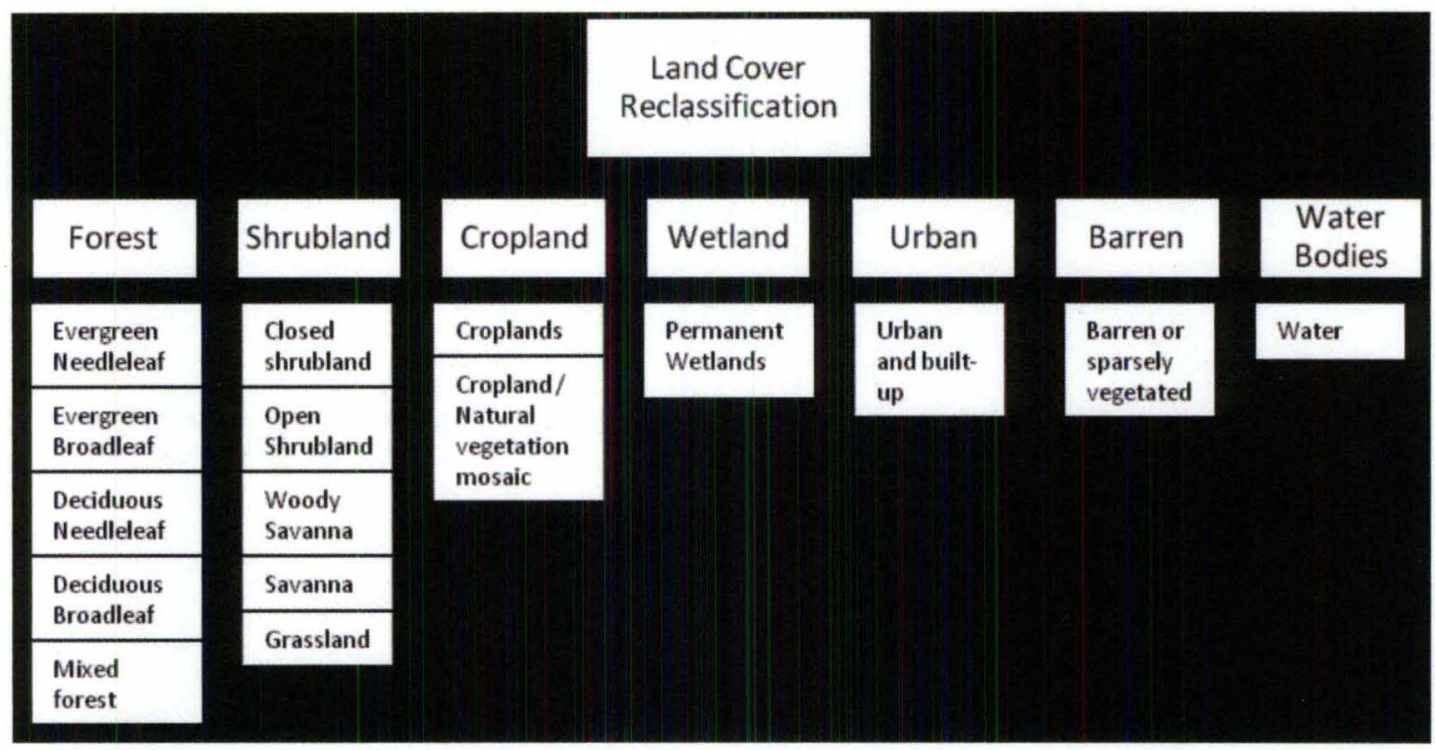

Figure 1. MODIS land cover classes aggregated for active fire classification.

The University of Maryland Fire Information for Resource Management System (FIRMS) was used to download Active Fire data points in a shapefile format for 2001 to 2010. Every hotspot detection (active fire) location is the centroid of an approximately 1 kilometer $(\mathrm{km})$ pixel that was identified as containing one or more actively burning hotspot/fire within that pixel. The MODIS active-fire algorithm uses the mid-infrared radiation from fires to examine each $500 \mathrm{~m}$ pixel and subsequently classify it as Missing data, Cloud, Water, Fire, Non-fire, or Unknown. Monthly Burned Area product from 2003 to 2010 was also acquired from the University of Maryland in a GEOTIFF format. Both the burned area product and the active fire points needed to be re-projected into WGS 1984 systems for mapping continuity when overlaid with the land cover products. Preprocessing of the monthly Burned Area product (MCD45A1) was done according to the MCD45A1 user guide. Burned area pixels and their associated burn date 
were selected and retained using raster calculator, while all other values were discarded. Next, the monthly burned area pixels were multiplied by the MODIS cropland land cover class, resulting in the number of burned area pixels that intersected cropland (Figure 2). A total of 12 months for 8 years in 7 provinces amounted to 672 processed MODIS burned area products. The results were broken down to the provincial level and summarized by season. The resolution of a MODIS burned area pixel is $463 \mathrm{~m}$ or $214,659 \mathrm{~m}^{\wedge} 2$, the area of which is multiplied by 0.0001 to obtain the area in hectares.

$$
B A p \times M C r(L C 12)=N C(b)
$$

MODIS Burned Area Pixel $x$ MODIS Cropland pixel $($ LC12 $)=$ Number of Cropland Pixels that Burned.

Initially three land cover products were considered: Globcover, Geobase, and MODIS. Each land cover product produced different spatial resolutions. A previous study of fire detection in British Columbia helped to verify the accuracy and reliability of each of the three land cover products (Kerr et al 2011). The comparison establishes a cross-validation for land cover classification at various resolutions and highlights differences between these three products. The MODIS Terra+Aqua Land Cover product MOD-12 (1000 m) incorporates five different land cover classification schemes, derived through a supervised decision-tree classification method. The scheme used for this study contains 17 classifications including 11 for vegetation.

GLOBCOVER $(300 \mathrm{~m})$ is a global land-cover map which was attained primarily from the MERIS sensor on-board the ENVISAT satellite. GLOBCOVER imagery was 
acquired over all twelve months of 2005. International remote sensing experts interpret the local land cover characteristics and provide data for the statistical assessment of map accuracies and ground-confirmation (ground-truthing) analysis.

The GeoBase (30 m resolution) land cover product is the result of vectorization of raster thematic data originating from classified Landsat 5 and Landsat 7 Ortho-images. Image dating spans from 1996 to 2005 . However, $80 \%$ of the land cover base comes from imagery taken from 1999 to 2001.

First, all of the data underwent preprocessing that allowed easy integration with each other and also limited their extent to British Columbia. From the MODIS Burned Area product only burned area pixels were retained and all other pixel classes eliminated. The Active Fire Product was divided into months so that it was comparable with the Burned Area product which is delivered in a monthly composite.

The land cover products were reclassified into 5 classes: Forest, Cropland, Grassland, Shrub land and Other (Figure 2). This aggregation of classes was necessary to simplify the comparison between the land cover products. Each product has a unique classification algorithm or methodology. Aggregating classes is a forced standardization process for comparing land cover products. All calculations were done in a GIS environment using ESRI ArcGIS 9.3.1 Spatial Analyst tools. Active Fires were designated to a land cover class based on their absolute location. The results were then summarized by month per year for every province.

Next, The Burned Area pixels were assigned to land cover classes based on each product. The raster format in the MODIS land cover product made it possible to utilize 
the raster calculator tool to multiply the burned area pixels with the land cover class. The result is a total pixel count per class.

The GeoBase product was converted from its original shapefile format into a raster format, reducing the file size and making it possible to for raster calculator operations to be performed. The GLOBCOVER product used Zonal Statistics to summarize the Burned Area pixels within the land cover classes. Burned area pixels were summarized by month per year for every province.

The results of the reclassified burned area and land cover products (GeoBase, GLOBCOVER and MODIS) can be seen in figures two through four. Burned area and active fire results were similar, both showing forest fire as the preeminent type detected in British Columbia, Canada. MODIS and GEOBASE both show Cropland burning while GLOBCOVER does not. The comparison reveals that both GEOBASE and MODIS provide sufficient accuracy for comparing fire detections and classifying land cover type. GLOBCOVER is not as resolute in its final mapping capabilities and excludes cropland land cover types. MODIS is most easily integrated with Active Fire and Burned Area data because of the shared source satellite and sensor system (Ernst et al. 2011).

Figure two (2) lists the 21 original MODIS LCP classifications underneath their respective re-classified land cover categories. The re-classified land cover categories encompass the dominant land cover types in Canada. 


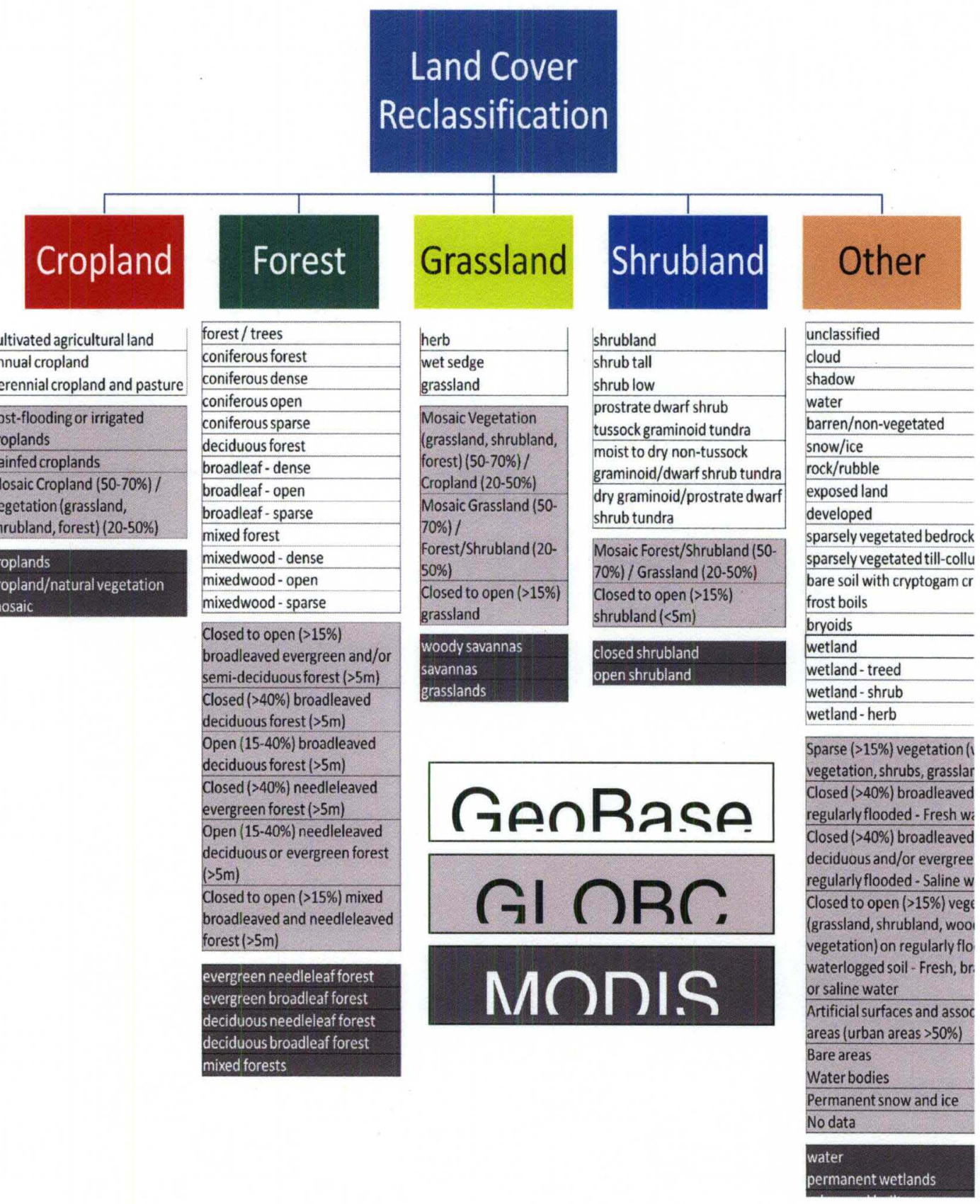

Figure 2. Original MODIS LCP classifications below their respective reclassified land cover type. 


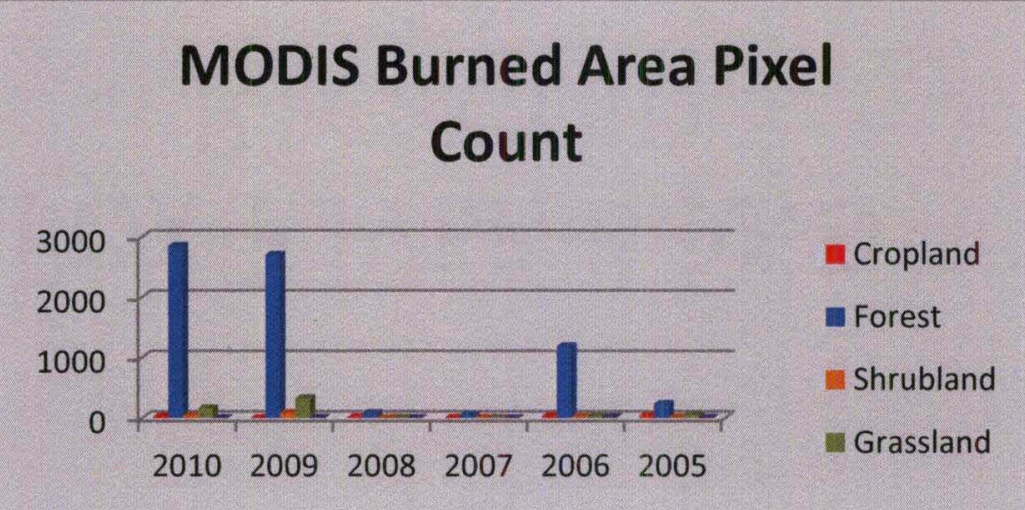

Figure 3. Count of MODIS Burned Area Pixels by re-classified land cover type.

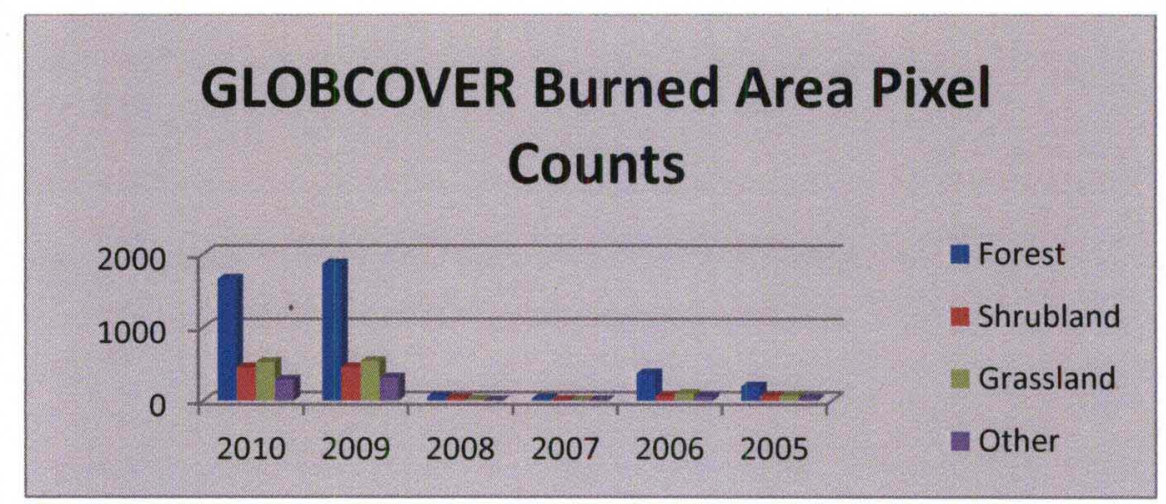

Figure 4. Count of GLOBCOVER Burned Area Pixels by re-classified land cover type.

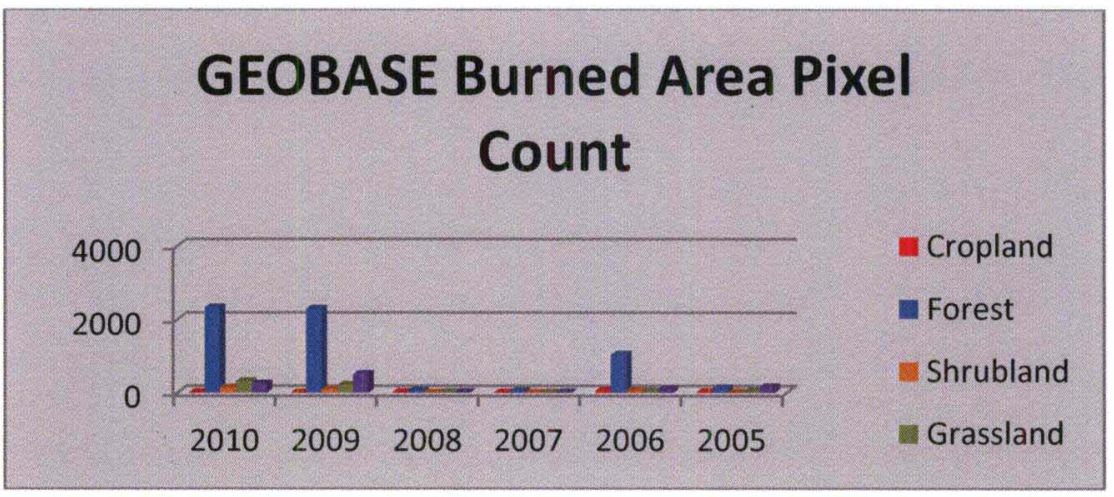

Figure 5. Count of MODIS Burned Area Pixels by re-classified land cover type. 


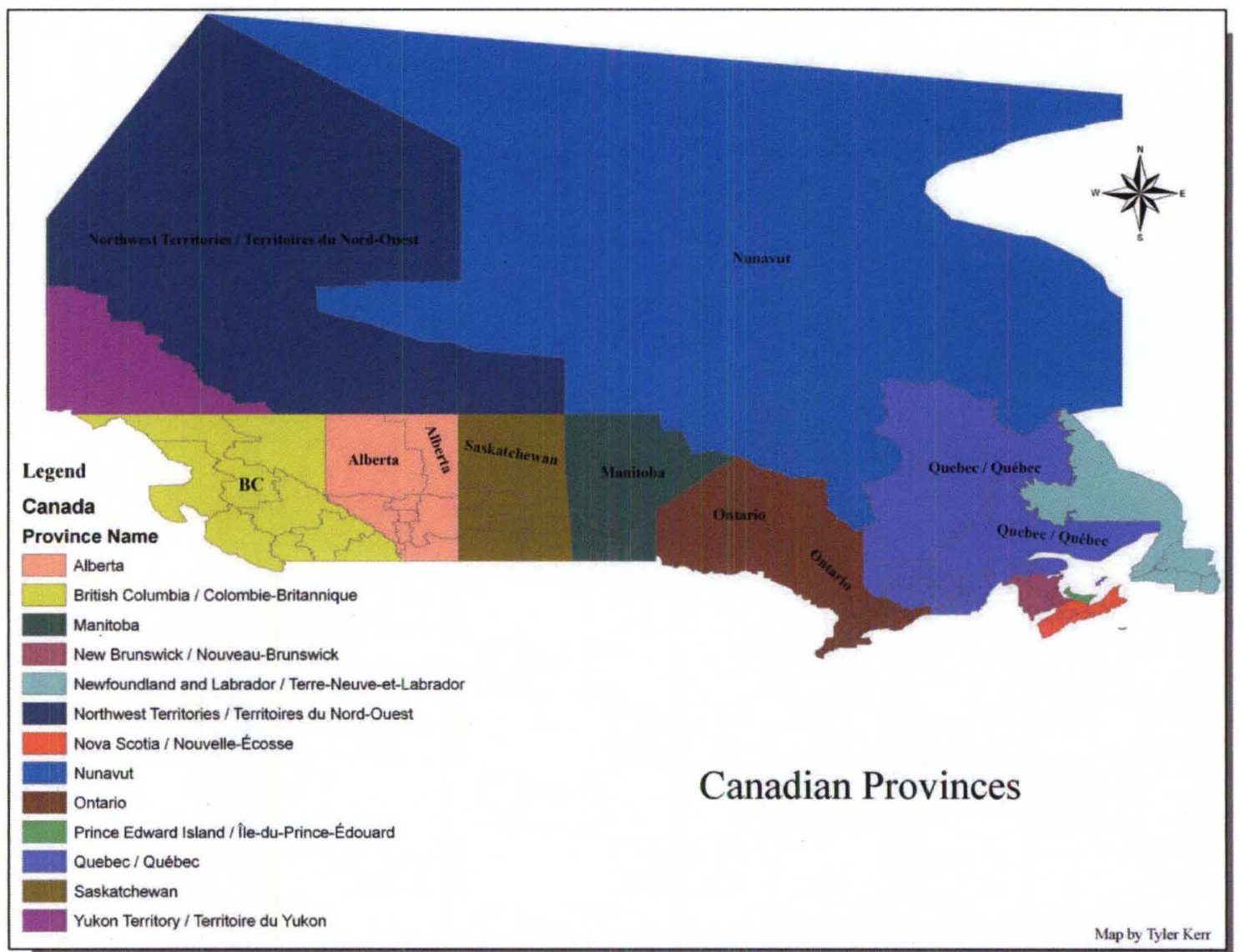

Figure 6. Map of Canadian Provinces.

\section{ANALYSIS PLAN}

Canadian fire detections by province for a time period of 2001 to 2010 will serve as a framework analysis model for future fire monitoring and emissions inventory estimates for local and international climate science and policy. As more data becomes available from year to year more accurate and comprehensive estimates will be able to be produced. This project serves as an addition to previous literature in analyzing methods to scientifically examine satellite data for the purpose of environmental and hazards monitoring. 


\section{RESULTS}

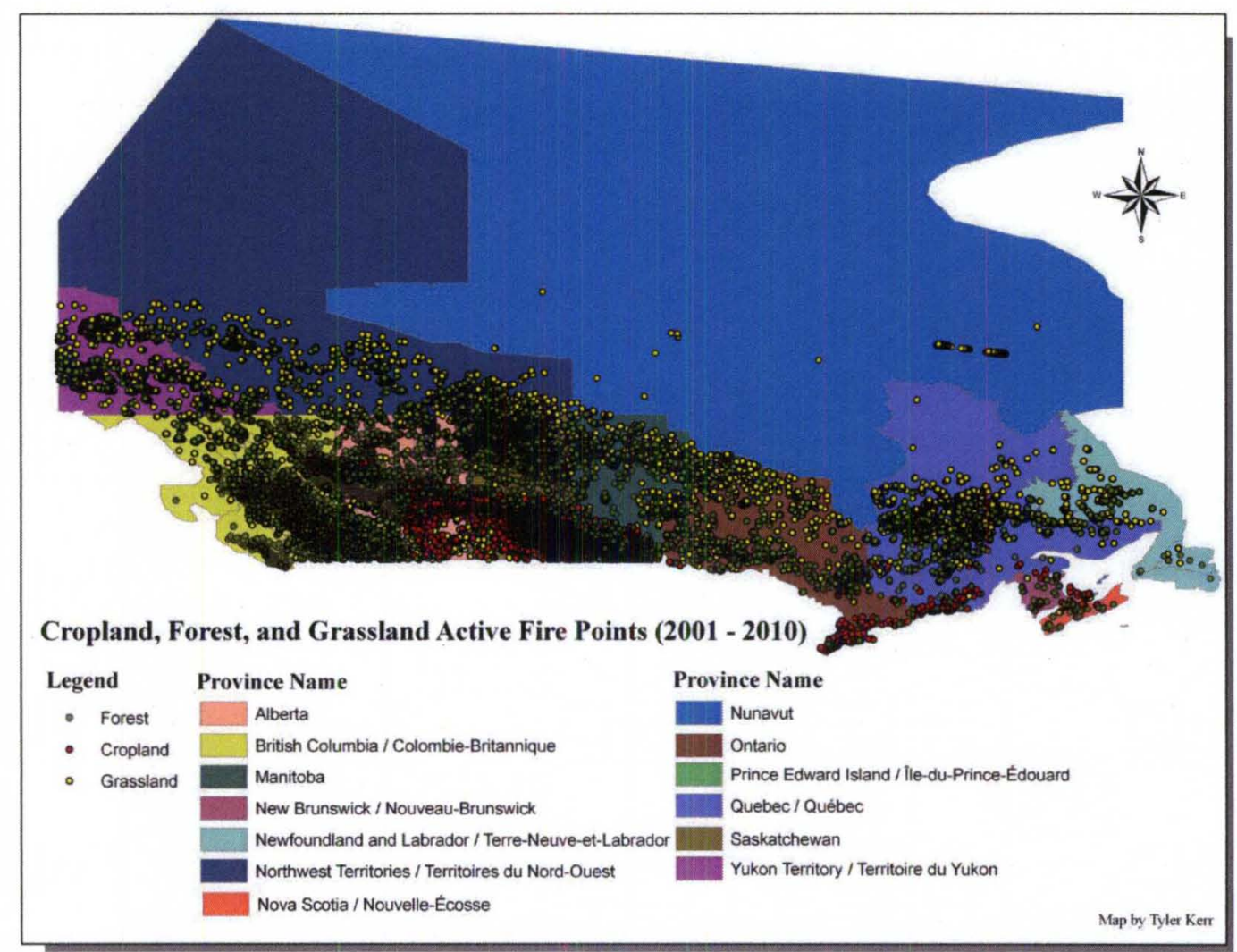

Figure 7. Cropland, Forest, and Grassland Active Fire points mapped to show general distribution over Canada.

The spatial distribution of fire is concentrated in the western provinces and especially in the prairie region (Figure 7). The results of the active fire land cover classification show that forest accounted for $65 \%$, shrubland for $19 \%$ and cropland for $13 \%$ of fire in the study area from 2001 to 2010 . Forest and shrubland burn across all of the provinces, but 
cropland fires are clustered in agriculturally intense areas. Years 2003 and 2010 had the highest number of recorded fires while 2001 and 2009 were the lowest.

Forest and shrubland have similar annual fire activity, perhaps due to wildfires starting and spreading between these two land cover types. Forest and shrub fires have large fluctuations in the number of fires per year, which could be related to climatic conditions and fire management. On the other hand, cropland fires are anthropogenic in origin and show a fairly consistent level of burning over the years.

Cropland burning has a distinctly different seasonal pattern compared to forest and shrubland burning (Figure 8). Springtime burning accounts for $61 \%$ of cropland fires, $32 \%$ of shrubland fires and $29 \%$ of forest fires. Summer fires account for $19 \%$ of cropland fires, $65 \%$ of shrubland fires, and $52 \%$ of forest fires. During the fall, $20 \%$ of cropland fires, $3 \%$ of shrubland fires, and $17 \%$ of forest fires occurred. Less than $1 \%$ of cropland, shrubland, and forest fires occur in the winter.

Forest fire detections are concentrated in British Columbia and northern Saskatchewan. Cropland fire detections are located in Saskatchewan and Manitoba, and extend to the Peace River agricultural area in Alberta along the border with British Columbia. The cropland area is an extension of the same region of the United States known for large farms producing crops such as wheat, corn, soybean, and rye. 


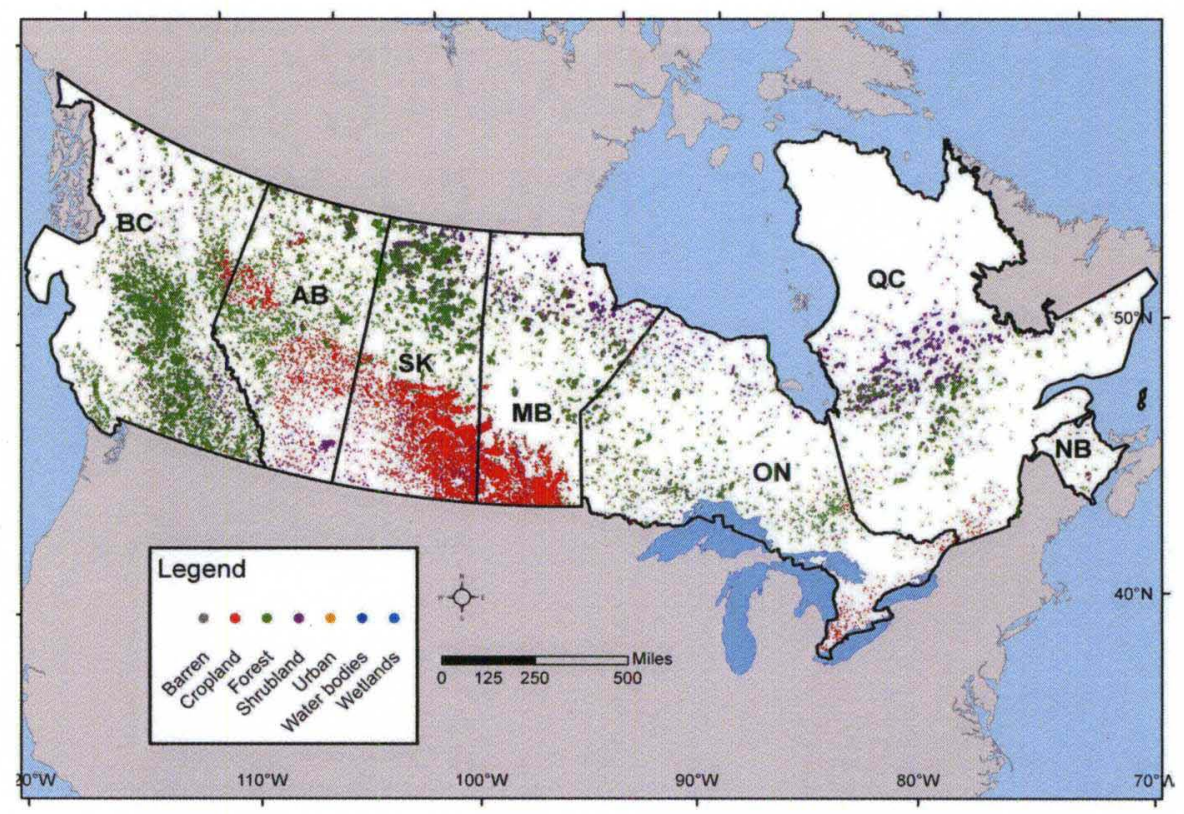

Figure 8. The location of active fires from 2001-10 identified by MODIS land cover type.

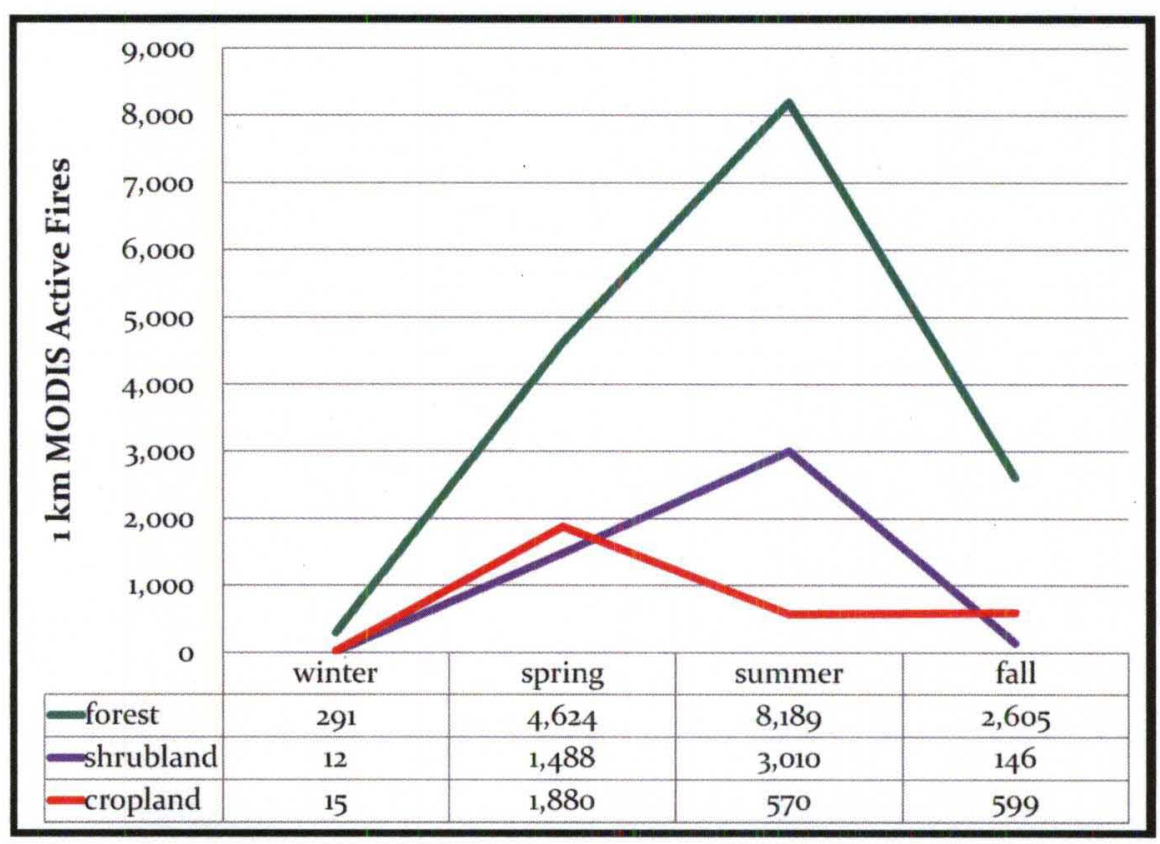

Figure 9. The average (2001-10) seasonality of the dominant land cover fires: cropland, forest, and shrubland. Seasons are winter (January - March); spring (April - June); summer (July - September); fall (October - December). 


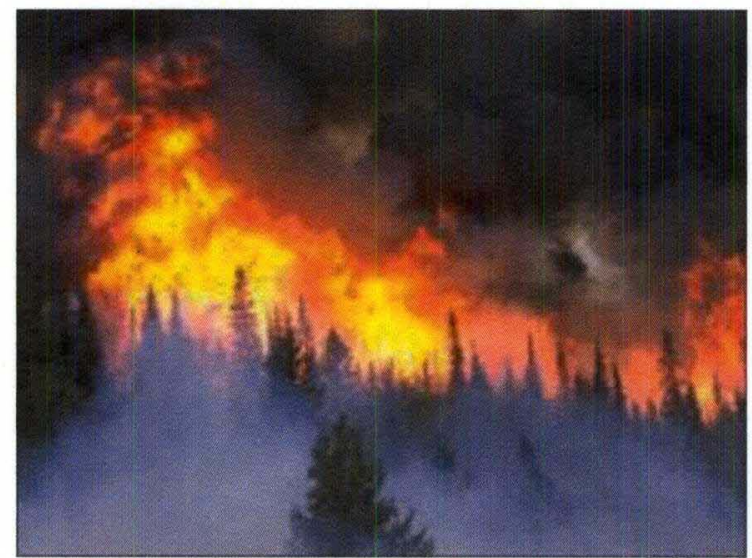

A. Forest fire in British Columbia
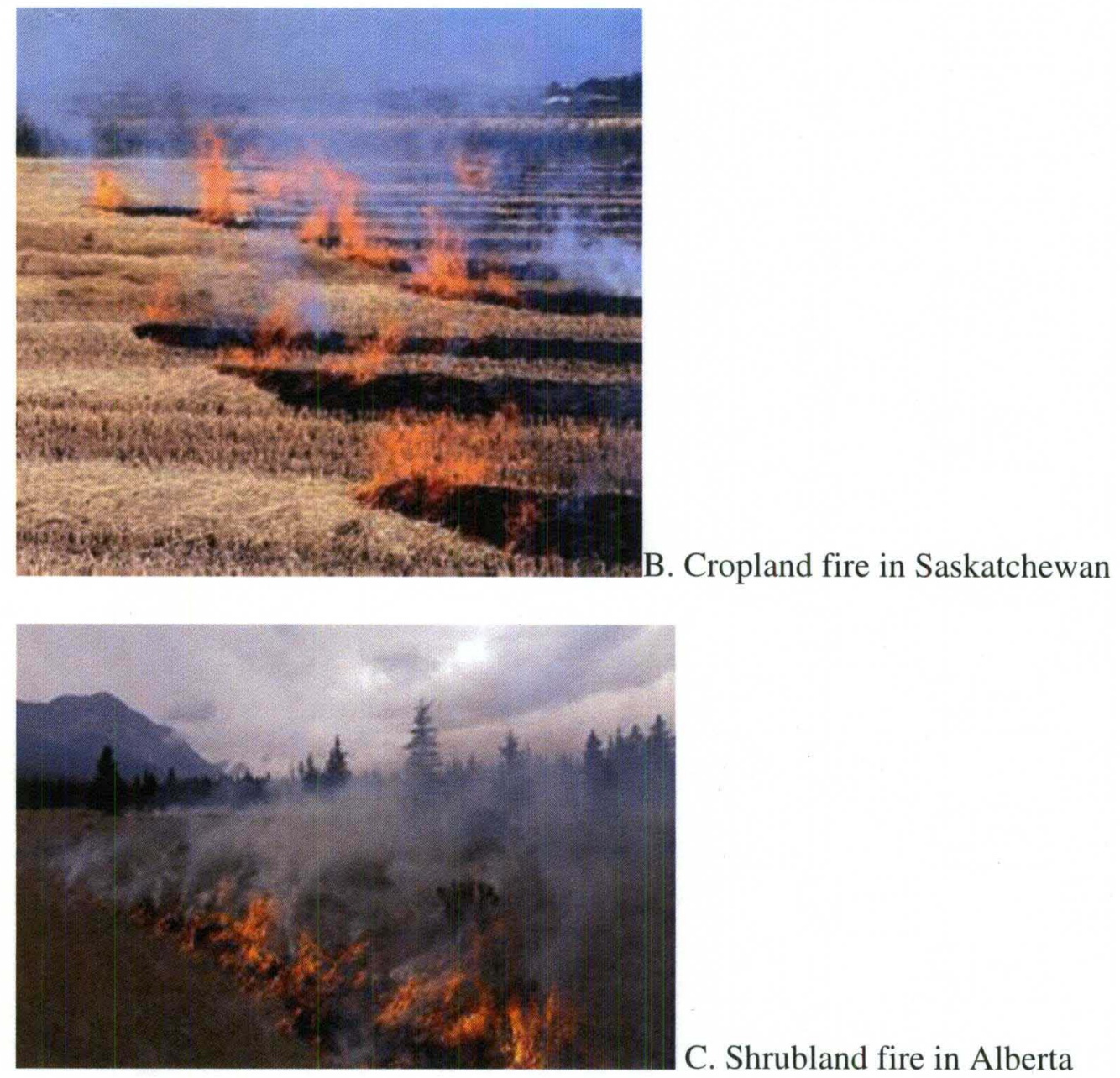

Figure 10 a-c. Fires in forest, cropland, and shrubland. 
On average from 2001-2010, the Prairie Provinces are the largest source of cropland active fire detections (Figure 8). Saskatchewan accounted for $46 \%$ of total cropland fires, followed by Manitoba 40\% and Alberta 10\% (Table 1). Spring is the season when all provinces burn the most cropland area. Fall burning occurs more frequently than summer, perhaps to clear the fields before fallowing them for the winter. The year 2004 had a low count of agricultural fire detections, followed by the highest number of agricultural fire detections in 2005 .

Of the cropland detected active fires $91 \%$ were located in the original MODIS land cover class cropland (LC 12) and 8\% in cropland/natural vegetation mosaic (LC 14). The MODIS burned area product was used to estimate the amount of cropland (LC 12) area that burned each season per province from 2003-2010 (Table 2). The results show that between 2003 and 2010, the top three provinces were on average Saskatchewan with 102,414 hectares, Manitoba with 77,858 hectares and Alberta with 35,823 hectares. The year 2005 experienced the most cropland burning, with $33 \%$ of all fires between 20032010 occurring. 2004 experienced the least, with $3 \%$ of total cropland burned area. The peak burned area months were May, September and October for all provinces.

Because of the concentrated nature of cropland burning it would seem that monitoring and regulation of agricultural emissions should be fairly manageable; however, it is a difficult and challenging task given the vast expanse of land that is Saskatchewan, Manitoba, and Alberta. 


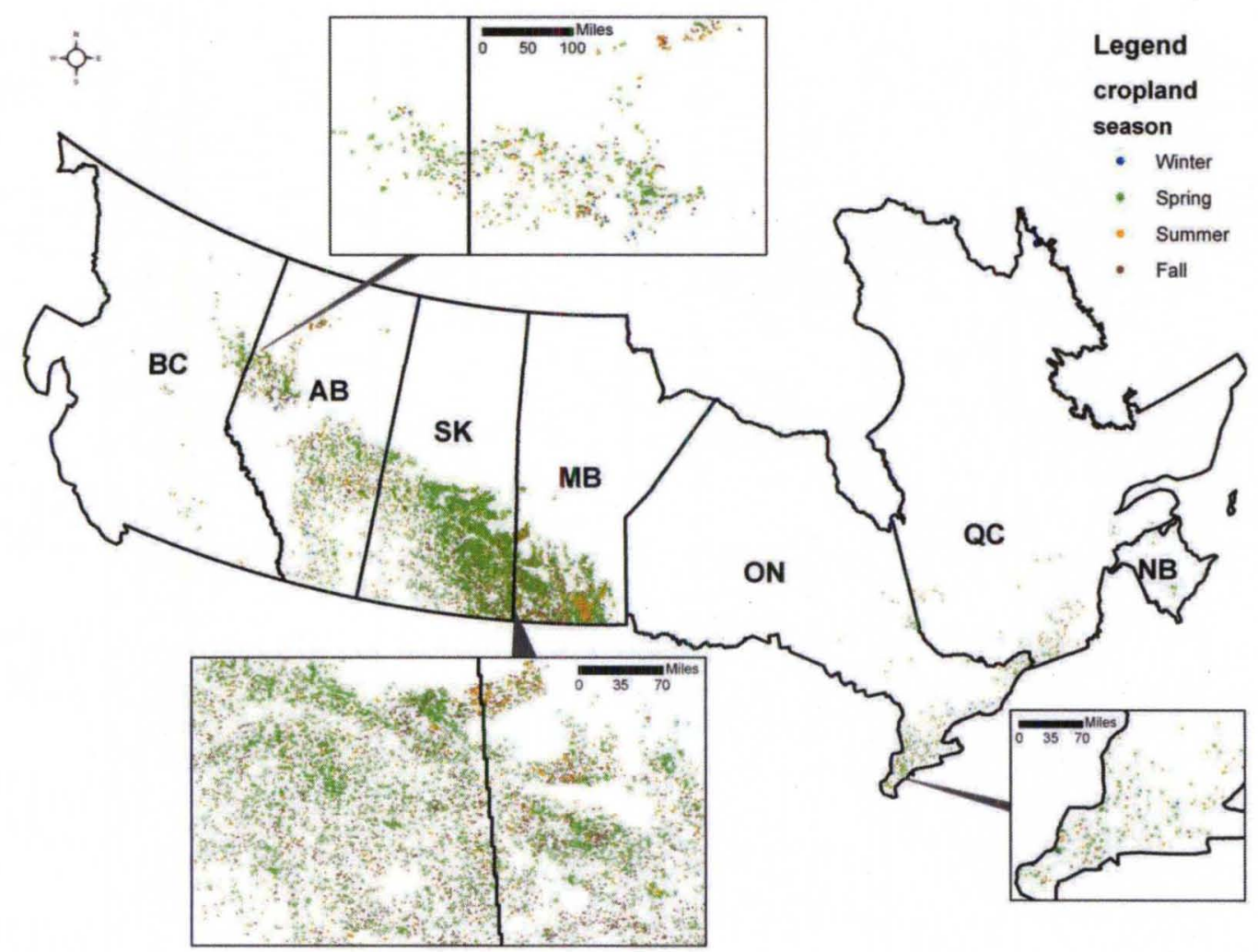

Figure 11. Seasonality of cropland active fires in Canada, 2001-10.

Table 1 below shows the raw count of AF detections in cropland (LC12 and LC14) by season for Canada and each province. Spring 2005 was the peak AF detection year in Canada (3,802 detections). Saskatchewan accounted for 2,093 of the 3,802 AF detections in spring 2005. This represents 55\% of the spring $2005 \mathrm{AF}$ detections. Saskatchewan produced the highest number of AF cropland detections of all provinces for every year except 2003, in which there were $839 \mathrm{AF}$ detections compared to $935 \mathrm{AF}$ detections in Manitoba. Alberta and Saskatchewan had their peak AF cropland detections in the spring season for every year while Manitoba shifted its peak AF cropland detections between spring and summer. 


\begin{tabular}{|c|c|c|c|c|c|c|c|c|c|c|c|c|}
\hline Area & Season & 2001 & 2002 & 2003 & 2004 & 2005 & 2006 & 2007 & 2008 & 2009 & 2010 & Average \\
\hline \multirow[t]{4}{*}{ Canada } & Winter & 13 & 6 & 19 & 11 & 8 & 29 & 4 & 7 & 2 & 53 & 15 \\
\hline & Spring & 881 & 1,336 & 2,001 & 937 & 3,802 & 1,892 & 1,502 & 1,891 & 2,235 & 2,323 & 1,880 \\
\hline & Summer & 668 & 805 & 601 & 137 & 448 & 767 & 744 & 484 & 602 & 443 & 570 \\
\hline & Fall & 380 & 228 & 961 & 713 & 312 & 450 & 835 & 932 & 519 & 662 & 599 \\
\hline \multirow[t]{4}{*}{ Alberta } & Winter & 8 & 4 & 14 & 10 & 7 & 22 & 4 & 7 & 1 & 11 & 9 \\
\hline & Spring & 180 & 174 & 142 & 168 & 311 & 257 & 91 & 152 & 205 & 132 & 181 \\
\hline & Summer & 92 & 173 & 11 & 38 & 34 & 44 & 41 & 43 & 91 & 60 & 63 \\
\hline & Fall & 78 & 79 & 43 & 50 & 67 & 12 & 46 & 54 & 56 & 71 & 56 \\
\hline British & Winter & 5 & 0 & 0 & 0 & 1 & 0 & 0 & 0 & 0 & 0 & 1 \\
\hline \multirow[t]{3}{*}{ Columbia } & Spring & 7 & 14 & 32 & 0 & 16 & 18 & 14 & 11 & 17 & 16 & 15 \\
\hline & Summer & 4 & 2 & 17 & 8 & 5 & 2 & 4 & 2 & 0 & 6 & 5 \\
\hline & Fall & 0 & 13 & 5 & 8 & 7 & 8 & 4 & 1 & 2 & 5 & 5 \\
\hline \multirow[t]{4}{*}{ Manitoba } & Winter & 0 & 0 & 5 & 0 & 0 & 0 & 0 & 0 & 0 & 28 & 3 \\
\hline & Spring & 133 & 305 & 935 & 355 & 1,303 & 354 & 520 & 570 & 833 & 609 & 592 \\
\hline & Summer & 350 & 462 & 404 & 41 & 259 & 454 & 576 & 317 & 388 & 238 & 349 \\
\hline & Fall & 181 & 106 & 386 & 502 & 75 & 244 & 420 & 400 & 329 & 290 & 293 \\
\hline \multirow[t]{4}{*}{ Saskatchewan } & Winter & 0 & 0 & 0 & 1 & 0 & 0 & 0 & 0 & 0 & 6 & 1 \\
\hline & Spring & 547 & 829 & 839 & 390 & 2,093 & 1,211 & 826 & 1,121 & 1,116 & 1,529 & 1,050 \\
\hline & Summer & 205 & 141 & 151 & 40 & 129 & 254 & 111 & 115 & 121 & 128 & 140 \\
\hline & Fall & 119 & 24 & 523 & 150 & 157 & 179 & 358 & 475 & 131 & 292 & 241 \\
\hline \multirow[t]{4}{*}{ Quebec } & Winter & 0 & 0 & 0 & 0 & 0 & 0 & 0 & 0 & 0 & 0 & 0 \\
\hline & Spring & 3 & 3 & 12 & 4 & 7 & 10 & 6 & 10 & 10 & 11 & 8 \\
\hline & Summer & 5 & 3 & 5 & 3 & 4 & 2 & 2 & 2 & 0 & 4 & 3 \\
\hline & Fall & 0 & 5 & 1 & 1 & 0 & 1 & 1 & 1 & 0 & 0 & 1 \\
\hline \multirow[t]{4}{*}{ Ontario } & Winter & 0 & 2 & 0 & 0 & 0 & 7 & 0 & 0 & 1 & 8 & 2 \\
\hline & Spring & 11 & 11 & 34 & 13 & 70 & 36 & 43 & 23 & 50 & 26 & 32 \\
\hline & Sumpmer & 12 & 22 & 12 & 7 & 17 & 11 & 10 & 5 & 2 & 6 & 10 \\
\hline & Fall & 2 & 1 & 3 & 2 & 6 & 6 & 6 & 1 & 1 & 4 & 3 \\
\hline
\end{tabular}

Table 1. Active fires detected in cropland (LC12 and 14) by season: Winter (January-March), spring (April-June), summer (July-September) and fall (October-December) with seasonal high shown in bold.

Table 2 below shows calculated burned area in hectares of cropland BA detections (LC12) by season for Canada and each province. Spring 2005 was the peak AF detection year in Canada (3,802 detections), accounting for 494,681 hectares of burned area. Saskatchewan accounted for 2,093 of the 3,802 AF detections in spring 2005, equating to 268,774 hectares of burned area. For Canada, the maximum area in hectares burned occurred in the spring season for every year from 2003 to 2010 except in 2004 (fall) and 2007 (summer). Saskatchewan is the only province to see its maximum burned 
area in the spring for every year from 2003 to 2010. The largest three areas of burned area detections are: Saskatchewan in spring 2005 (268,774 hectares), Alberta in spring 2005 (145,989 hectares), and Saskatchewan in spring 2006 (106,728 hectares).

\begin{tabular}{|c|c|c|c|c|c|c|c|c|c|c|}
\hline Area & Season & 2003 & 2004 & 2005 & 2006 & 2007 & 2008 & 2009 & 2010 & Average \\
\hline \multirow[t]{4}{*}{ Canada } & Winter & 129 & 0 & 0 & 0 & 0 & 43 & 0 & 193 & 46 \\
\hline & Spring & 105,805 & 22,947 & 494,681 & 163,978 & 26,725 & 74,336 & 103,015 & 66,179 & 132,208 \\
\hline & Summer & 71,116 & 4,422 & 71,932 & 127,765 & 56,541 & 26,575 & 10,647 & 53,429 & 52,803 \\
\hline & Fall & 104,281 & 25,995 & 6,225 & 26,961 & 14,039 & 36,964 & 150 & 58,044 & 34,082 \\
\hline \multirow[t]{4}{*}{ Alberta } & Winter & 0 & 0 & 0 & 0 & 0 & 21 & 0 & 21 & 5 \\
\hline & ring & 2,232 & 4,680 & 145,989 & 43,511 & 8,865 & 1,889 & 11,377 & 10,754 & 28,662 \\
\hline & Summer & 9,209 & 1,352 & 2,919 & 11.463 & 1,073 & 8,415 & 258 & 1,610 & 4,537 \\
\hline & Fall & 11,570 & 687 & 1,073 & 794 & 4,186 & 1,782 & 0 & 859 & 2,619 \\
\hline British & Winter & 0 & 0 & 0 & 0 & 0 & 0 & 0 & 0 & 0 \\
\hline \multirow[t]{3}{*}{ Columbia } & Spring & 43 & 64 & 730 & 343 & 0 & 0 & 0 & 0 & 148 \\
\hline & Summer & 558 & 0 & 64 & 21 & 150 & 322 & 21 & 258 & 174 \\
\hline & Fall & 107 & 21 & 0 & 0 & 0 & 0 & 0 & 301 & 54 \\
\hline \multirow[t]{4}{*}{ Manitoba } & Winter & 129 & 0 & 0 & 0 & 0 & 0 & 0 & 172 & 38 \\
\hline & Spring & 43,747 & 10,647 & 79,059 & 12,729 & 2,962 & 10,797 & 18,353 & 17,581 & 24,485 \\
\hline & Summer & 41,086 & 1,266 & 64,805 & 37,222 & 51,046 & 11,119 & 2,597 & 35,590 & 30,592 \\
\hline & Fall & 60,276 & 24,900 & 3,134 & 23,570 & 3,456 & 23,333 & 0 & 43,275 & 22,743 \\
\hline \multirow[t]{4}{*}{ Saskatchewan } & Winter & 0 & 0 & 0 & 0 & 0 & 21 & 0 & 0 & 3 \\
\hline & Spring & 59,353 & 7,170 & 268,774 & 106,728 & 14,811 & 61,521 & 72,877 & 37,737 & 78,621 \\
\hline & Summer & 11,313 & 751 & 3,456 & 78,780 & 3,971 & 5,281 & 4,916 & 14,468 & 15,367 \\
\hline & Fall & 31,898 & 365 & 1,975 & 2,447 & 6,204 & 11,055 & 0 & 13,438 & 8,423 \\
\hline \multirow[t]{4}{*}{ Quebec } & Winter & 0 & 0 & 0 & 0 & 0 & 0 & 0 & 0 & 0 \\
\hline & Spring & 0 & 0 & 0 & 0 & 0 & 0 & 0 & 0 & 0 \\
\hline & Summer & 580 & 386 & 215 & $\mathbf{0}$ & 0 & 21 & 43 & 365 & 201 \\
\hline & Fall & 150 & 21 & 21 & 86 & 21 & 0 & 21 & 0 & 40 \\
\hline \multirow[t]{4}{*}{ Ontario } & Winter & 0 & 0 & 0 & 0 & 0 & 0 & 0 & 0 & 0 \\
\hline & Spring & 429 & 386 & 129 & 408 & 43 & 0 & 408 & 64 & 233 \\
\hline & Summer & 8,372 & 665 & 472 & 258 & 301 & 1,417 & 2,812 & 1,138 & 1,929 \\
\hline & Fall & 279 & 0 & 21 & 64 & 172 & 794 & 129 & 172 & 204 \\
\hline
\end{tabular}

Table 2. Burned area in hectares detected in cropland (LC 12) by season: Winter (January-March), spring (April-June), summer (July-September) and fall (October-December) with seasonal high shown in bold. 


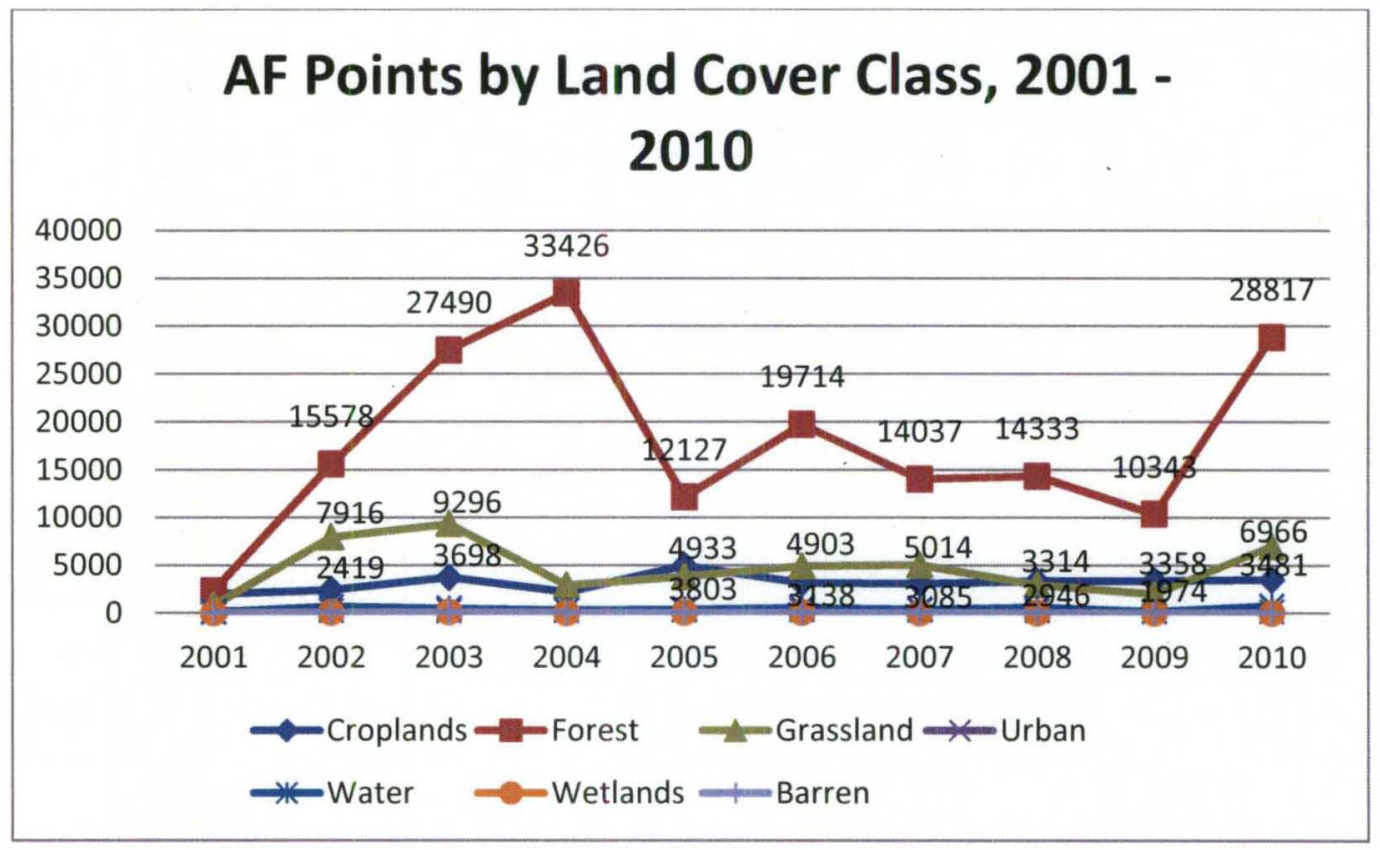

Figure 12. Canadian AF points by land cover classification for 2001 to 2010.

The Forest land cover class accounts for the greatest number of fires during any given year from 2001 to 2010. Grassland accounts for the second most numerous amounts of active fire detections for this time period. Grasslands serve as the boundary layer between agricultural and pastoral lands and forest regions.

Forest land cover types have an abundant fuel load to supply fires with the energy to spread across large tracts of land. Grasslands and Cropland land covers, however, offer significantly lower fuel load potentials. Active fire cropland detections outnumbered the Grassland detections in 2005 and 2009.

Active fire detections for Cropland land cover have been steady and consistent since 2006. This could be attributed to "repeat offending" farmers burning residue from 
year to year; however, qualitative survey analysis would be necessary to confirm or deny this

postulation. Active fire detections in the Forest land cover class have been the most erratic, and are correlative to the number of forest fires and the ability of fire fighting response units to prevent, manage, and reduce the spread of each fire for any given year. Water, wetlands, barren land cover classes produced insignificant detections, and are most likely being classified as an Active Fire due to the reflectance of the surface at the time the sensor passes and scans the ground. Urban fires also produced a significantly lower number of Active Fire detections.

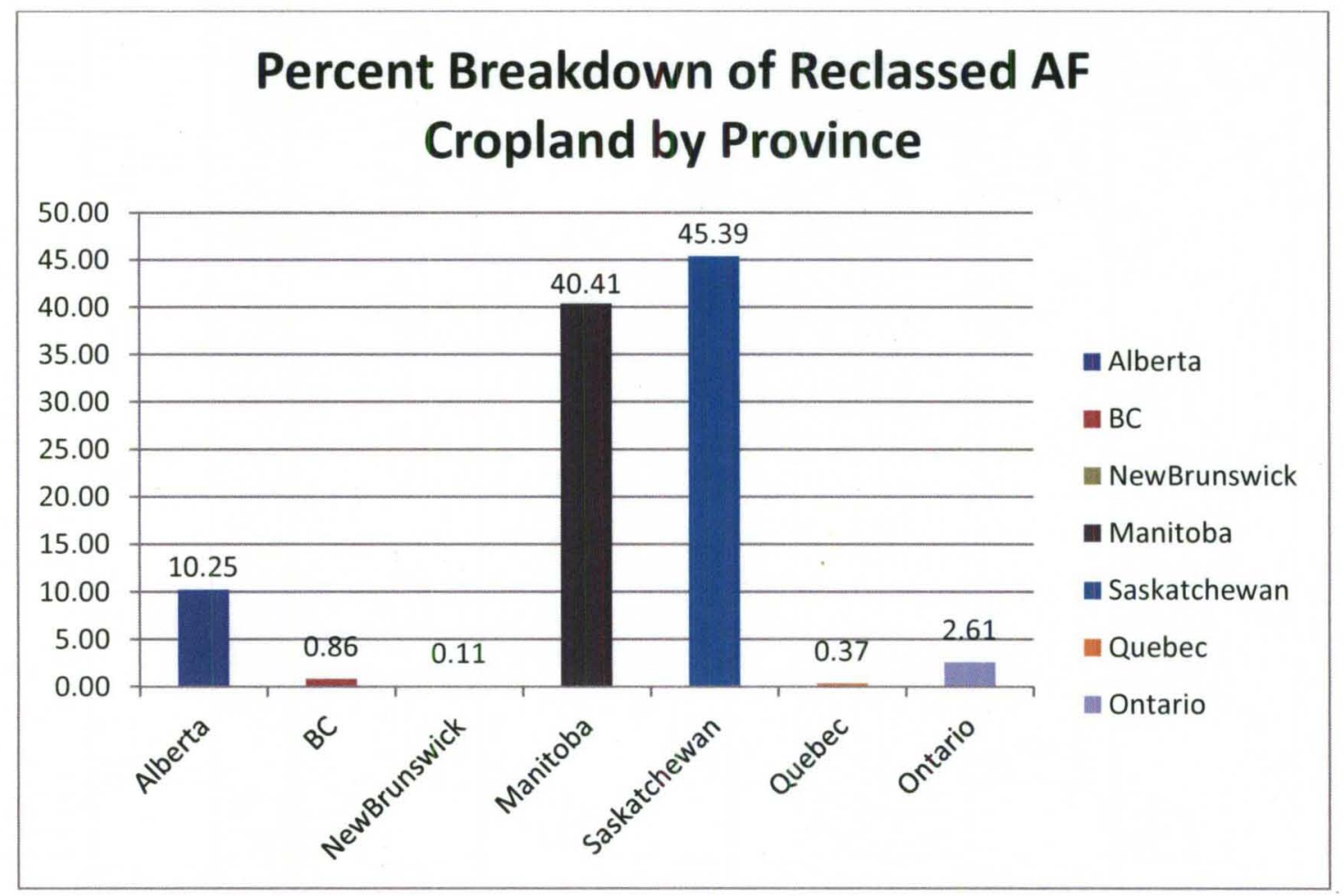

Figure 13. Percent of AF Cropland points by province.

The "Bread Basket" provinces of Saskatchewan, Manitoba, and Alberta produced the greatest number of Active Fire detections in the cropland land cover category from 
2001 to 2010. British Columbia, New Brunswick, Quebec, and Ontario produced significantly lower

numbers of Active Fire detections for the period of 2001 to 2010. The Yukon Territories, Prince Edward Island, Newfoundland, Nunavut, Nova Scotia, and the Northwest Territories had no Cropland burning.

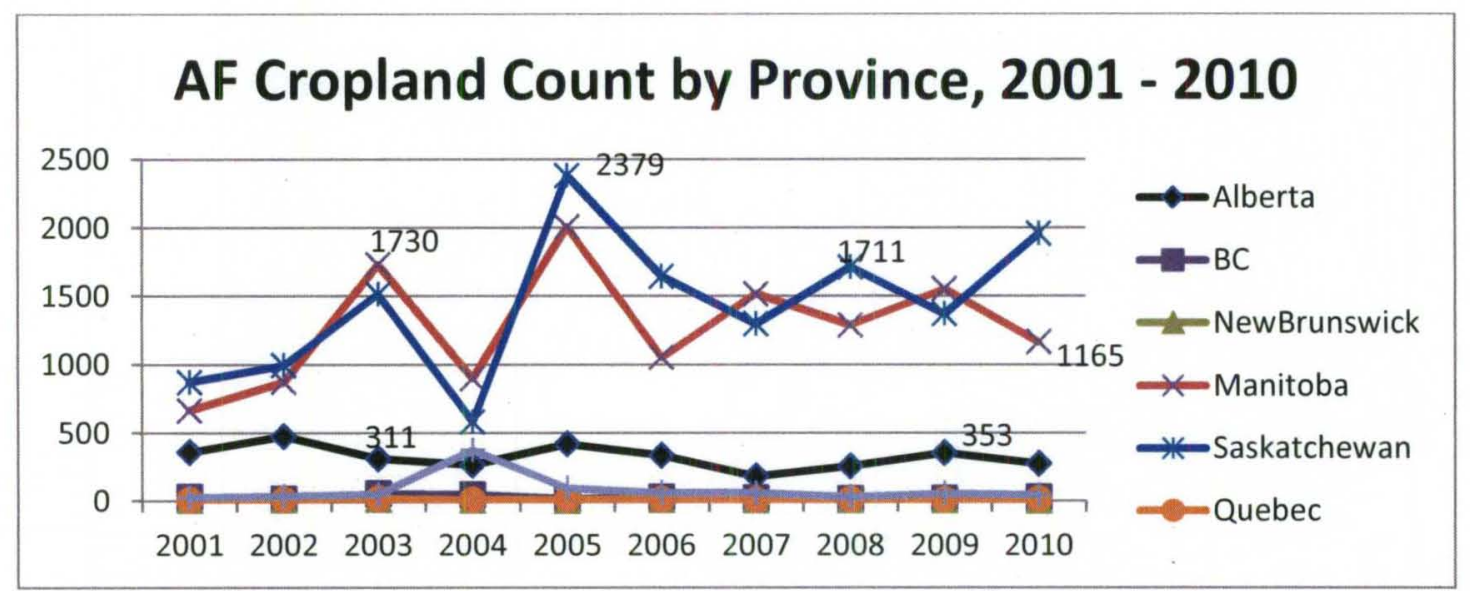

Figure 14. Number of AF detections cropland by province from 2001 to 2010.

Saskatchewan had its peak Cropland fires in 2005 with a count of 2,379 Active Fire detections. Manitoba also peaked in 2005 with nearly 2,000 Active Fire detections in the Cropland land cover category. Alberta peaked in 2002 with approximately 500 Active Fire detections in the Cropland land cover class. 


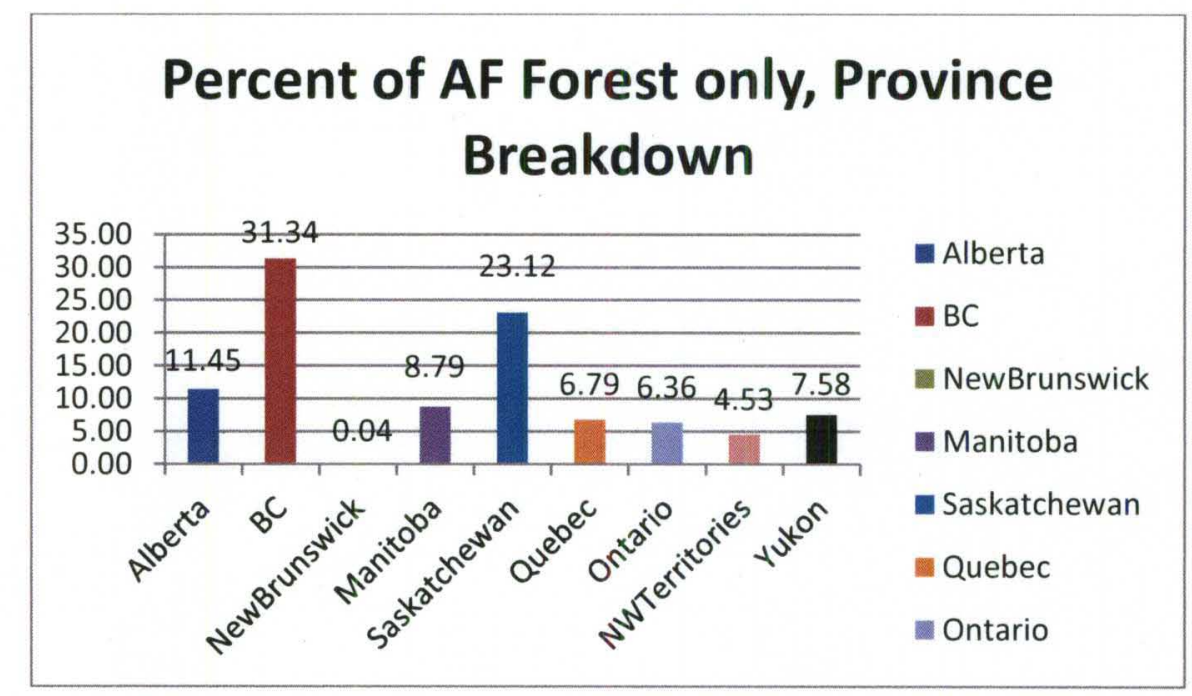

Figure 15. Percent of AF Forest points by province.

British Columbia and Saskatchewan account for the largest percentage of Active Fire detections in the Forest land cover category. Alberta accounts for the third most Forest class active fire detections. The rest of the Forest class AF detections are equally distributed amongst Manitoba, the Yukon, Quebec, and Ontario. The Northwest Territories and New Brunswick are the least significant contributors to AF Forest class detections amongst the provinces detecting AF Forest fires. Nova Scotia, Prince Edward Island, Nunavut, and Newfoundland had zero AF detections in the Forest land cover class. The large percentage of fires in British Columbia occurs in forest; this allows for specific planning for fire management teams in the province. 


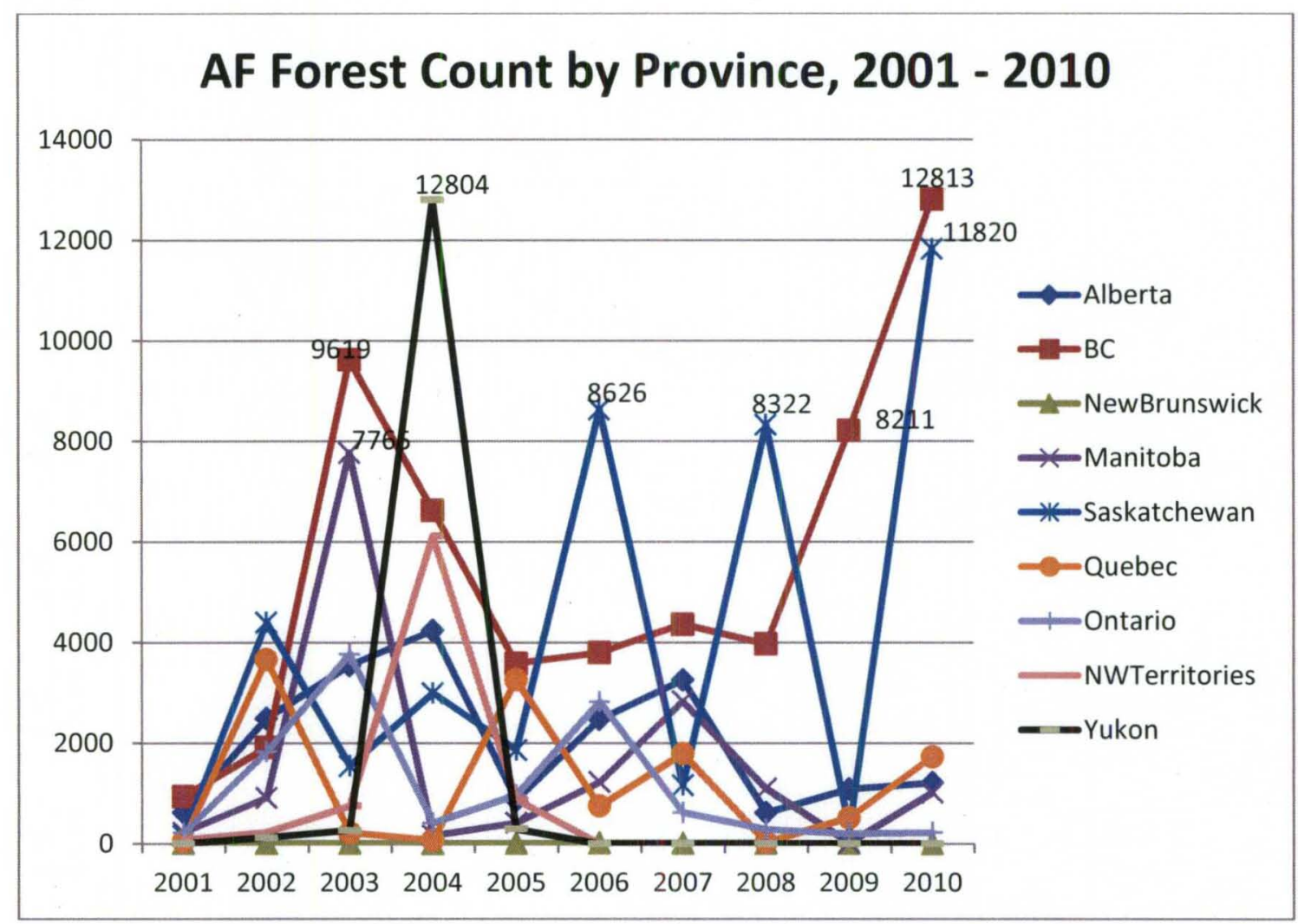

Figure 16. Number of AF detections forest by province from 2001 to 2010.

Despite only accounting for $7.58 \%$ of the total AF Forest detections, the Yukon produced the second highest number of AF Forest detections of all provinces in any single year in 2004 with 12,804 pings. 2004 was the only significant year of AF Forest detections for the Yukon and the Northwest Territories. This can be attributed to a year that has been recorded as one of the driest and warmest in the region spanning from Northern Alaska into the Northwest Territories and the Yukon (Eamer 2004). British Columbia (31.34\%) recorded the highest number of AF Forest detections of all provinces in any given year in 2010 with 12,813 pings. There is no consistent pattern in AF Forest detections from year to year for any of the Provinces. This is attributable to the weather 
conditions of each province in each year as well as to the ability of fire management teams to prevent, manage, and control the spread of fires on a year to year basis.

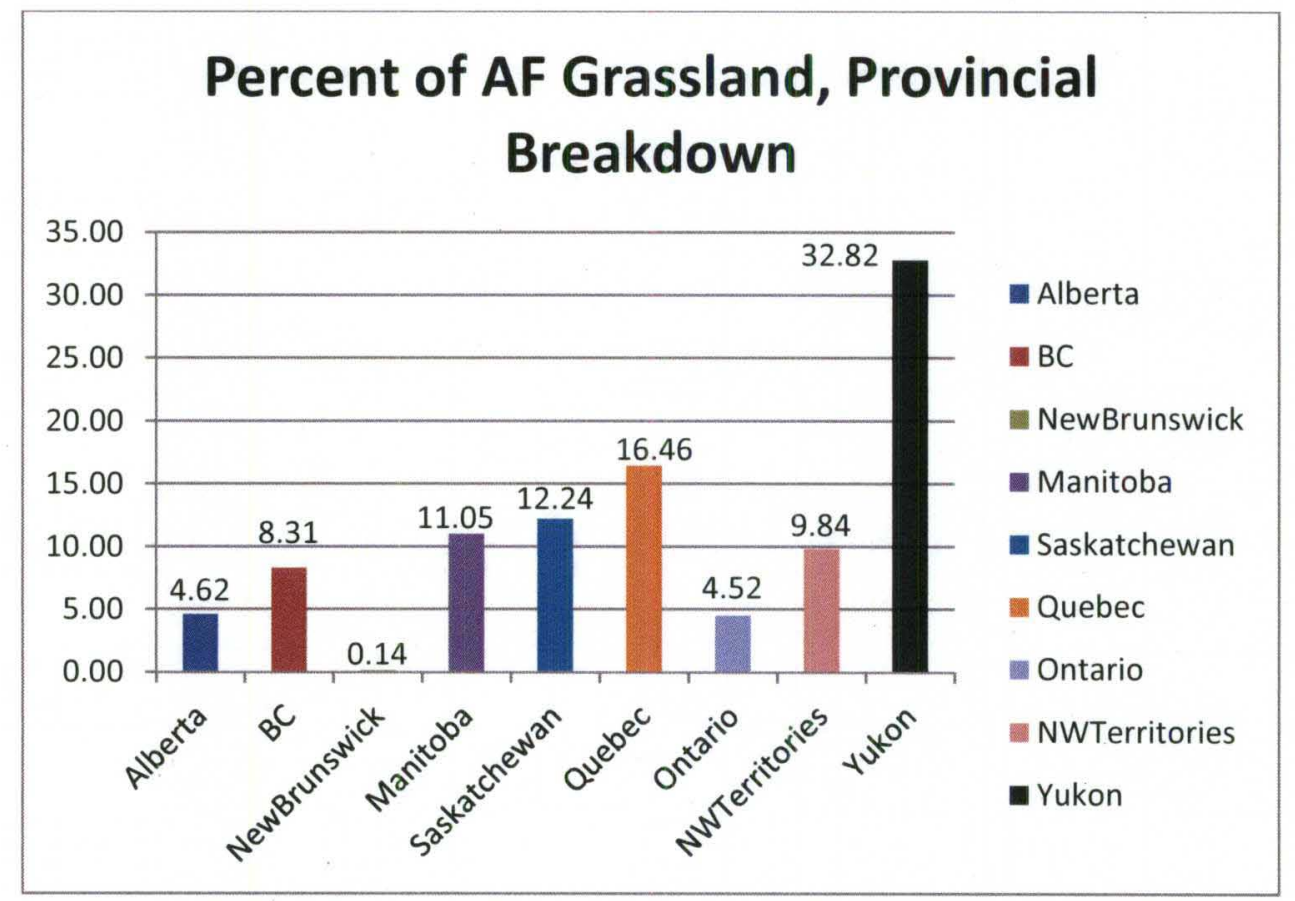

Figure 17. Percent of AF Grassland points by province.

The Yukon territories accounted for the largest percentage of AF grassland detections for the time period of 2001 - 2010, representing $32.82 \%$ of all AF pings in the Grassland land cover class. Quebec was the second largest contributor, accounting for $16.46 \%$. Manitoba and Saskatchewan, located side by side, accounted for a collective total of $23.29 \%$ of total AF Grassland detections. Nova Scotia, Prince Edward Island, Nunavut, and Newfoundland did not contribute to the AF Grassland detections for 2001 2010. 


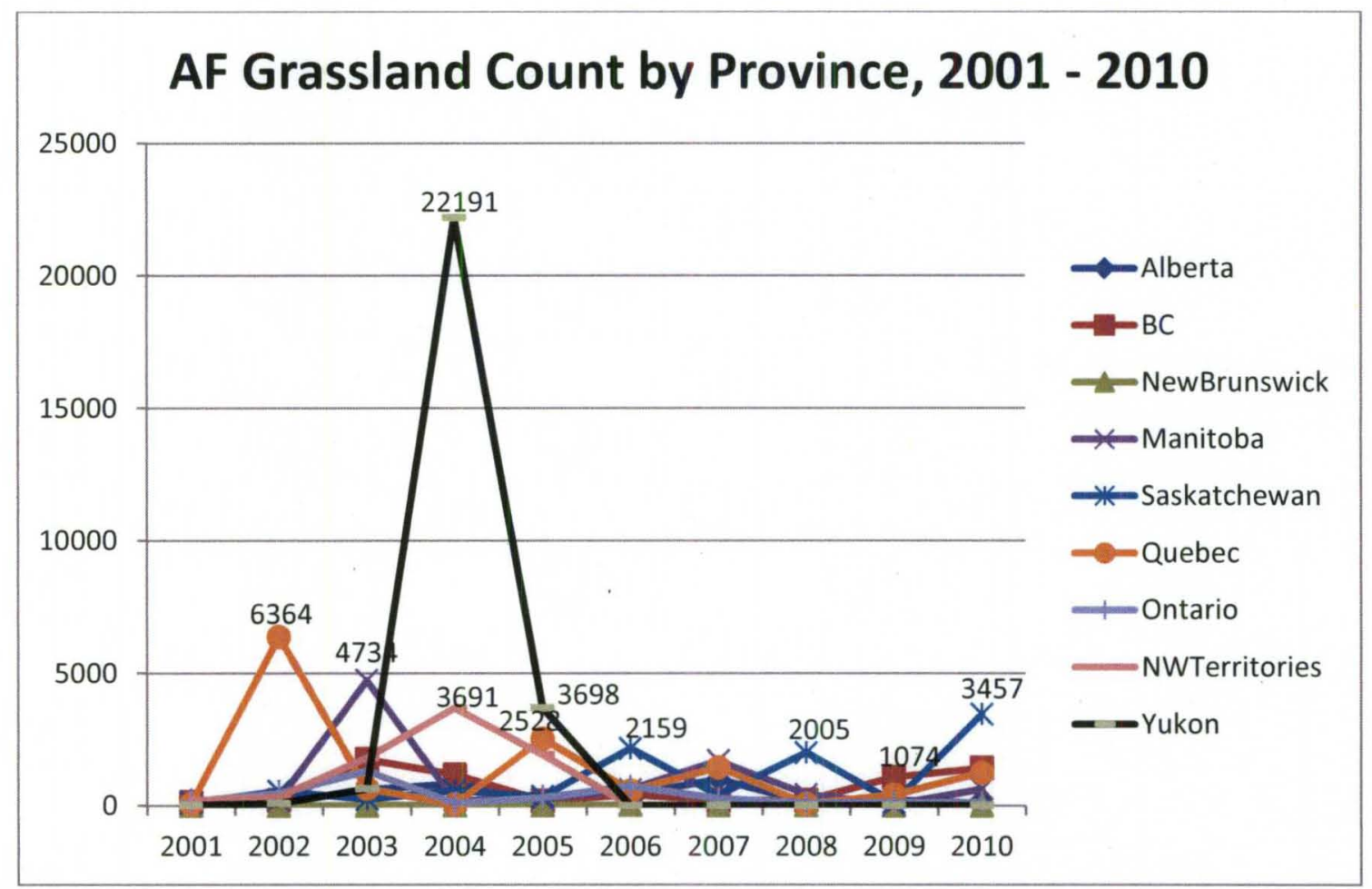

Figure 18. Number of AF detections grassland by province from 2001 to 2010.

2004 was a peak fire season in the Northwest corner of Canada comprising the provincial areas of the Yukon and the Northwest Territories. These peaks attribute the large percentage of AF grassland detections for the Yukon. The total number of AF Grassland detections for 2001 to 2010 is 26,633 ; however, there were $22,191 \mathrm{AF}$ Grassland detections in 2004 alone. Similarly for the Northwest Territories there were a total of 7,984 AF Grassland detections with 3,691 occurring in 2004 alone. This represents $46.2 \%$ of the total AF Grasslands from 2001 to 2010 in the Northwest Territories.

Much of the burning throughout the year in Canada occurs in the Western provinces because of the extensive tracts of land. The Eastern Provinces have less forest 
and agricultural lands and retain more of the population of Canada with exception of large cities in the West such as Vancouver, Edmonton, and Calgary.

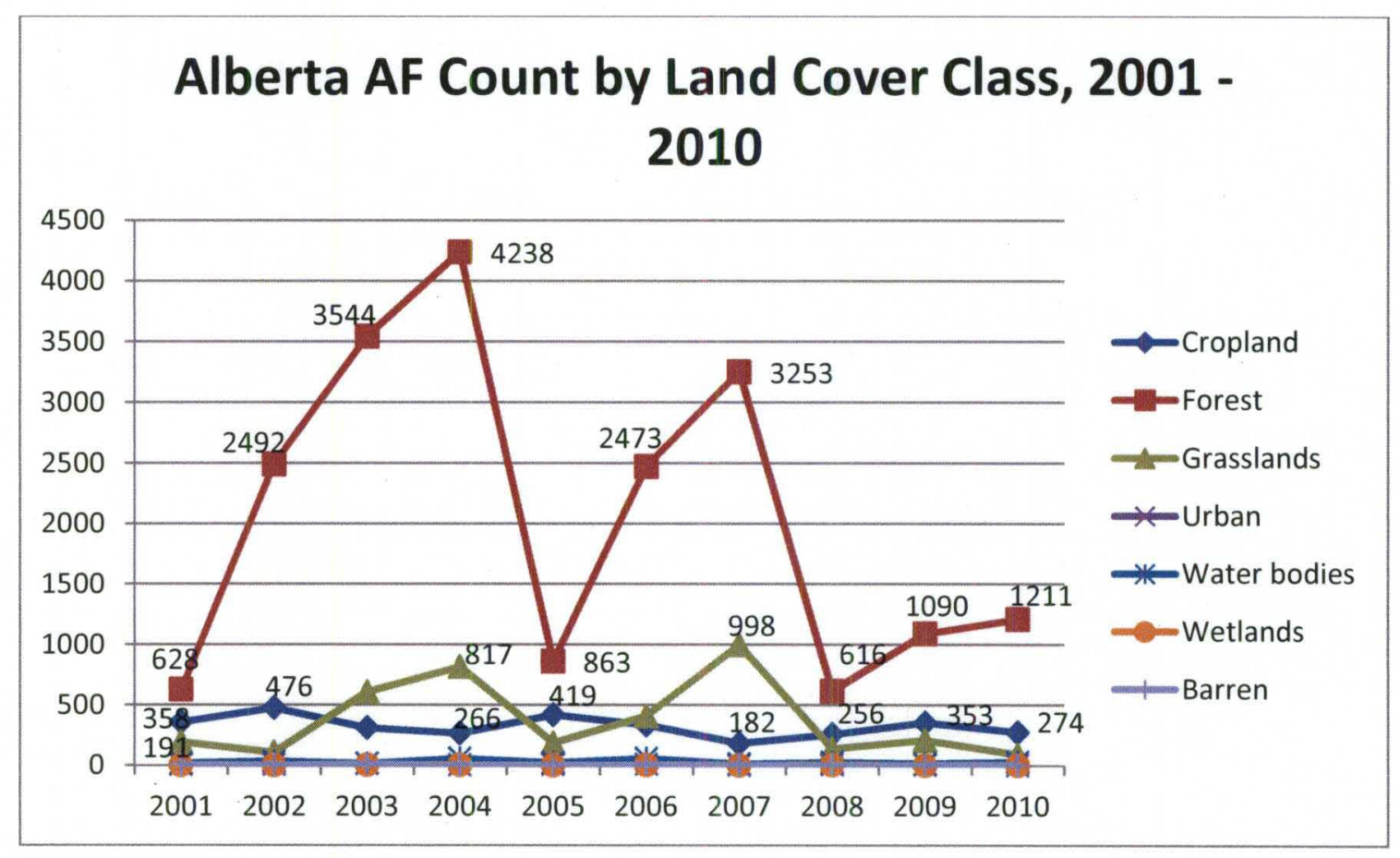

Figure 19. Number of AF detections by land cover class for Alberta from 2001 to 2010.

The Forest land cover class accounted for the largest number of AF detections in Alberta from 2001 to 2010. There were 27,773 total AF detections in Alberta for the study period, of which 20,408 were classified as Forest land cover. Forest land cover accounted for $73.5 \%$ of the total AF detections in Alberta from 2001 to 2010. The peak fire year in Alberta for forest fires was 2004 (4,238 detections), followed closely by 2003 (3,544 detections) and 2007 (3,253 detections). $2004 \mathrm{AF}$ forest detections account for $15.3 \%$ of the total AF detections in Alberta from 2001 to 2010; $2003 \mathrm{AF}$ forest detections account for $12.8 \%$, and $2007 \mathrm{AF}$ forest detections account for $11.7 \%$ during the same 
time span. The table below shows the total AF counts for Alberta broken down by land cover classification for each year in the study period.

\begin{tabular}{|l|l|l|l|l|l|l|l|l|l|l|l|}
\hline Alberta & $\underline{\mathbf{0 1}}$ & $\underline{\mathbf{0 2}}$ & $\underline{\mathbf{0 3}}$ & $\underline{\mathbf{0 4}}$ & $\underline{\mathbf{0 5}}$ & $\underline{\mathbf{0 6}}$ & $\underline{\mathbf{0 7}}$ & $\underline{\mathbf{0 8}}$ & $\underline{\mathbf{0 9}}$ & $\underline{\mathbf{1 0}}$ & $\underline{\text { Total }}$ \\
\hline Cropland & 358 & 476 & 311 & 266 & 419 & 335 & 182 & 256 & 353 & 274 & 3230 \\
\hline Forest & 628 & 2492 & 3544 & 4238 & 863 & 2473 & 3253 & 616 & 1090 & 1211 & 20408 \\
\hline Grasslands & 191 & 108 & 608 & 817 & 186 & 408 & 998 & 138 & 208 & 90 & 3752 \\
\hline Urban & 4 & 6 & 12 & 5 & 7 & 10 & 2 & 8 & 3 & 1 & 58 \\
\hline Water & $\mathbf{1 8}$ & 34 & 16 & 57 & 22 & 57 & 13 & 26 & 14 & 28 & 285 \\
\hline Wetlands & 0 & 0 & 3 & 3 & 0 & 3 & 0 & 4 & 0 & 0 & 13 \\
\hline Barren & 7 & 0 & 11 & 0 & 0 & 3 & 2 & 0 & 3 & 1 & 27 \\
\hline & 1206 & 3116 & 4505 & 5386 & 1497 & 3289 & 4450 & 1048 & 1671 & 1605 & 27773 \\
\hline
\end{tabular}

Table 3. Raw number count of AF detections for Alberta from 2001 to 2010.

The Grassland classification accounted for $13.5 \%$ of the total AF detections in Alberta while the Cropland classification accounted for $11.6 \%$. The peak AF year for Grassland detections in Alberta was 2007 (998 detections) followed by 2004 (816 detections) and 2003 (608 detections.

The peak AF year for Forest detections was 2004 (4238 detections) followed by 2003 (3544 detections) and 2007 (3253 detections). Cropland AF detections peaked in 2002 (476) followed by 2005 (419) and 2001 (358). Water bodies, Wetlands, and Barren land cover categories were most likely classified as such due to the reflectance values collected by the MODIS sensor being close to the programmed values for the presence of fire. 


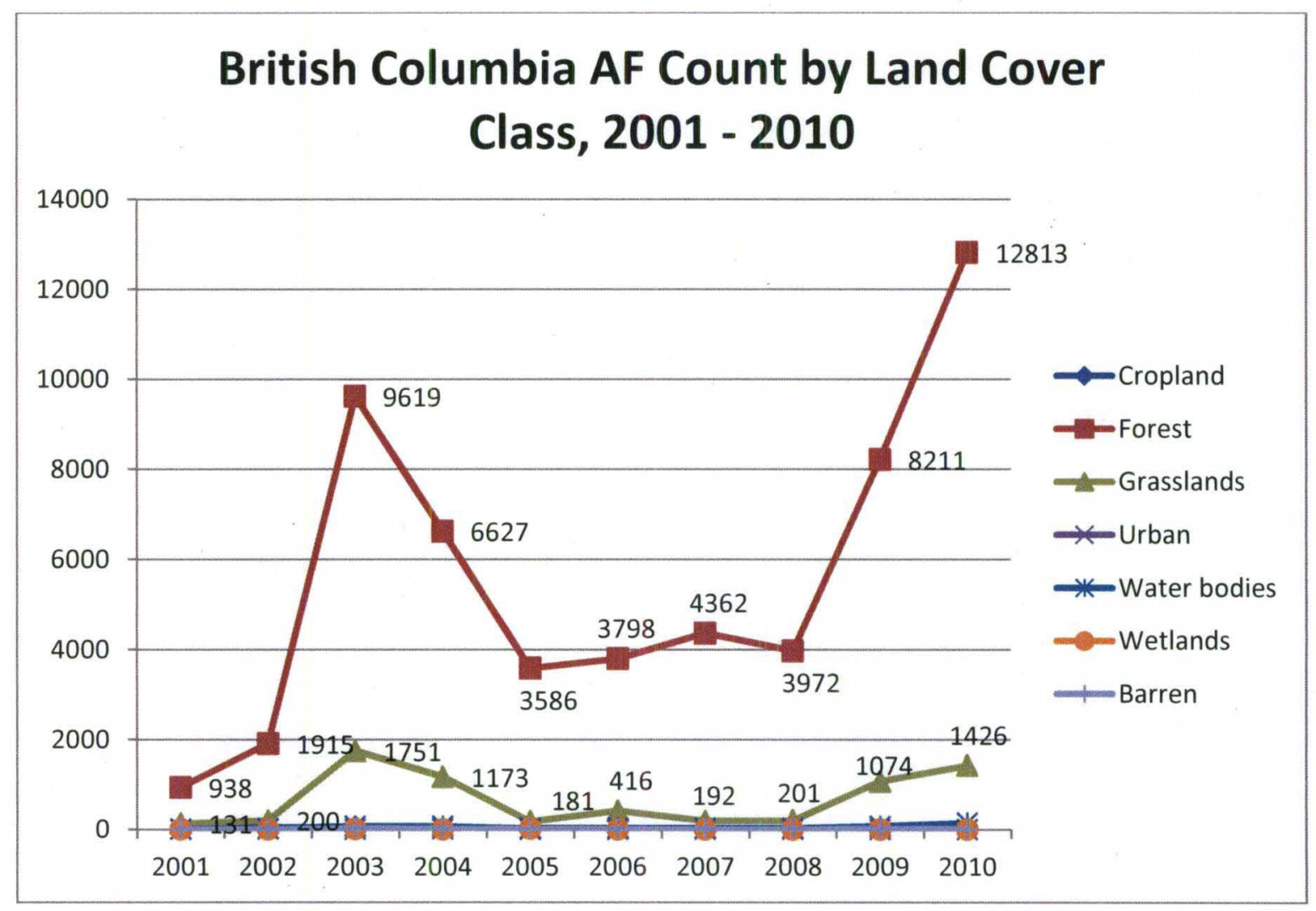

Figure 20. Number of AF detections by land cover class for British Columbia from 2001 to 2010 .

There were a total of 63,477 AF detections in British Columbia from 2001 to 2010. British Columbia AF detections were most numerous for the Forest classification followed by Grasslands. Forest AF detections accounted for $88 \%$ of the total AF detections in British Columbia while Grasslands represents $10.6 \%$. There was insignificant Cropland burning (271 detections) in British Columbia.

The peak AF year for the Forest classification was 2010 (12,813 detections) followed by 2003 (9,619 detections) and 2009 (8,211 detections). 2010 forest AF detections accounted for $20.2 \%$ of the total AF detections in British Columbia from 2001 to 2010 . The peak AF fire year for the Grasslands classification was $2003(1,751$ 
detections) followed by 2010 (1,426 detections) and 2004 (1,173 detections). The 2003 grasslands AF detections accounted for $2.6 \%$ of the total AF detection in British Columbia from 2001 to 2010 . The peak fire year for Cropland was 2003 (54 detections).

\begin{tabular}{|l|l|l|l|l|l|l|l|l|l|l|l|}
\hline BC & $\mathbf{6} \mathbf{0 1}$ & $\underline{\mathbf{6 2}}$ & $\underline{\mathbf{0 3}}$ & $\underline{\mathbf{0 4}}$ & $\underline{\mathbf{6 0 5}}$ & $\underline{\mathbf{0 6}}$ & $\underline{\mathbf{0 7}}$ & $\underline{\mathbf{6 0}}$ & $\underline{\mathbf{0 9}}$ & $\underline{\mathbf{1 0}}$ & $\underline{\mathbf{T o t a l}}$ \\
\hline Cropland & 16 & 46 & 54 & 16 & 29 & 28 & 22 & 14 & 19 & 27 & 271 \\
\hline Forest & 938 & 1915 & 9619 & 6627 & 3586 & 3798 & 4362 & 3972 & 8211 & 12813 & 55841 \\
\hline Grasslands & 131 & 200 & 1751 & 1173 & 181 & 416 & 192 & 201 & 1074 & 1426 & 6745 \\
\hline Urban & 0 & 6 & 3 & 6 & 3 & 2 & 4 & 0 & 4 & 0 & 28 \\
\hline Water & 13 & 20 & 73 & 72 & 22 & 32 & 31 & 26 & 75 & 148 & 512 \\
\hline Wetlands & 0 & 0 & 8 & 0 & 16 & 3 & 0 & 0 & 5 & 4 & 36 \\
\hline Barren & 0 & 0 & 18 & 9 & 0 & 0 & 7 & 0 & 10 & 0 & 44 \\
\hline & 1098 & 2187 & 11526 & 7903 & 3837 & 4279 & 4618 & 4213 & 9398 & 14418 & 63477 \\
\hline
\end{tabular}

Table 4. Raw number count of AF detections for British Columbia from 2001 to 2010.

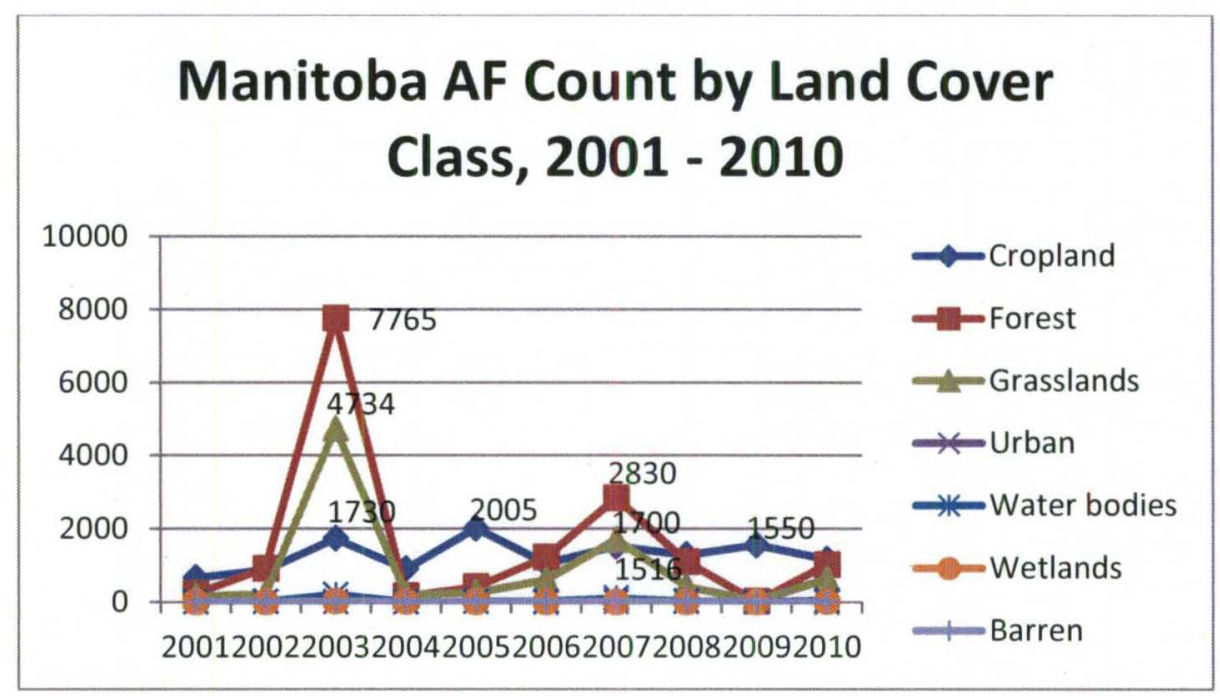

Figure 21. Number of AF detections by land cover class for Manitoba from 2001 to 2010. 
There were a total of 37,923 AF detections in Manitoba. In Manitoba from 2001 to 2010, the most AF detections fell into the Forest classification $(15,670)$ followed by Cropland (12,740) and Grasslands (8,968). Forest accounted for $41.3 \%$ of AF detections in Manitoba from 2001 to 2010; Cropland accounted for 33.6\%, and Grasslands accounted for $23.6 \%$. The peak AF year for the Forest classification was $2003(7,765$ detections) followed by 2007 (2,830 detections). The 2003 forest AF detections accounted for $20.5 \%$ of all of the AF detections in Manitoba from 2001 to 2010 . The peak AF year for the Cropland classification was 2005 (2005 detections) followed by 2003 (1,730 detections) and 2009 (1,550 detections). The 2005 cropland AF detections accounted for $5.6 \%$ of the total AF detections in Manitoba from 2001 to 2010. The peak AF year for the Grasslands classification was 2003 (4,734 detections) followed by 2007 (1,400 detections). The 2003 Grasslands AF detections accounted for $12.5 \%$ of the total AF detections in Manitoba from 2001 to 2010.

\begin{tabular}{|l|l|l|l|l|l|l|l|l|l|l|l|}
\hline Manitoba & $\underline{\mathbf{0 1}}$ & $\underline{\mathbf{0 2}}$ & $\underline{\mathbf{0 3}}$ & $\underline{\mathbf{0 4}}$ & $\underline{\mathbf{0 5}}$ & $\underline{\mathbf{0 6}}$ & $\underline{\mathbf{0 7}}$ & $\underline{\mathbf{0 8}}$ & $\underline{\mathbf{0 9}}$ & $\underline{\mathbf{1 0}}$ & $\underline{\text { Total }}$ \\
\hline Cropland & 664 & 873 & 1730 & 898 & $\mathbf{2 0 0 5}$ & 1052 & 1516 & 1287 & 1550 & 1165 & 12740 \\
\hline Forest & 224 & 915 & 7765 & 164 & 414 & 1224 & 2830 & 1098 & 19 & 1017 & 15670 \\
\hline Grasslands & 166 & 222 & 4734 & 202 & 254 & 604 & 1700 & 423 & 37 & 626 & 8968 \\
\hline Urban & 2 & 4 & 3 & 1 & 9 & 2 & 7 & 9 & 5 & 0 & 42 \\
\hline Water & 4 & 16 & 202 & 3 & 15 & 31 & 109 & 31 & 6 & 51 & 468 \\
\hline Wetlands & 0 & 0 & 25 & 3 & 0 & 1 & 1 & 0 & 0 & 5 & 35 \\
\hline Barren & 0 & 0 & 0 & 0 & 0 & 0 & 0 & 0 & 0 & 0 & 0 \\
\hline & 1060 & 2030 & 14459 & 1271 & 2697 & 2914 & 6163 & 2848 & 1617 & 2864 & 37923 \\
\hline
\end{tabular}

Table 5. Raw number count of AF detections for Manitoba from 2001 to 2010. 
There were 67,164 total AF detections in Saskatchewan from 2001 to 2010 . The Forest land cover category accounted for the $61.3 \%$ of AF detections $(41,191)$ in Saskatchewan from 2001 to 2010. Cropland (14,311) accounted for the second most $(21.3 \%)$ and the Grassland $(9,931)$ classification accounted for the third most, or $14.8 \%$ of the total AF detections in Saskatchewan from 2001 to 2010. The peak AF year for the Forest classification was 2010 (11,820 detections) followed by 2006 (8,626 detections) and 2008 (8,322 detections). The peak AF year for the Cropland classification was 2005 (2,379 detections) followed by 2010 (1,955 detections) and 2003 (1,513 detections.) The peak AF year for the Grasslands classification was 2010 (3,457 detections) followed by 2006 (2,159 detections) and 2008 (2,005 detections). Water bodies accounted for $2.4 \%$ of the total AF detections in Saskatchewan while Urban, Wetlands, and Barren land cover classes totaled less than $1 \%$ of the total AF counts for the province from 2001 to 2010.

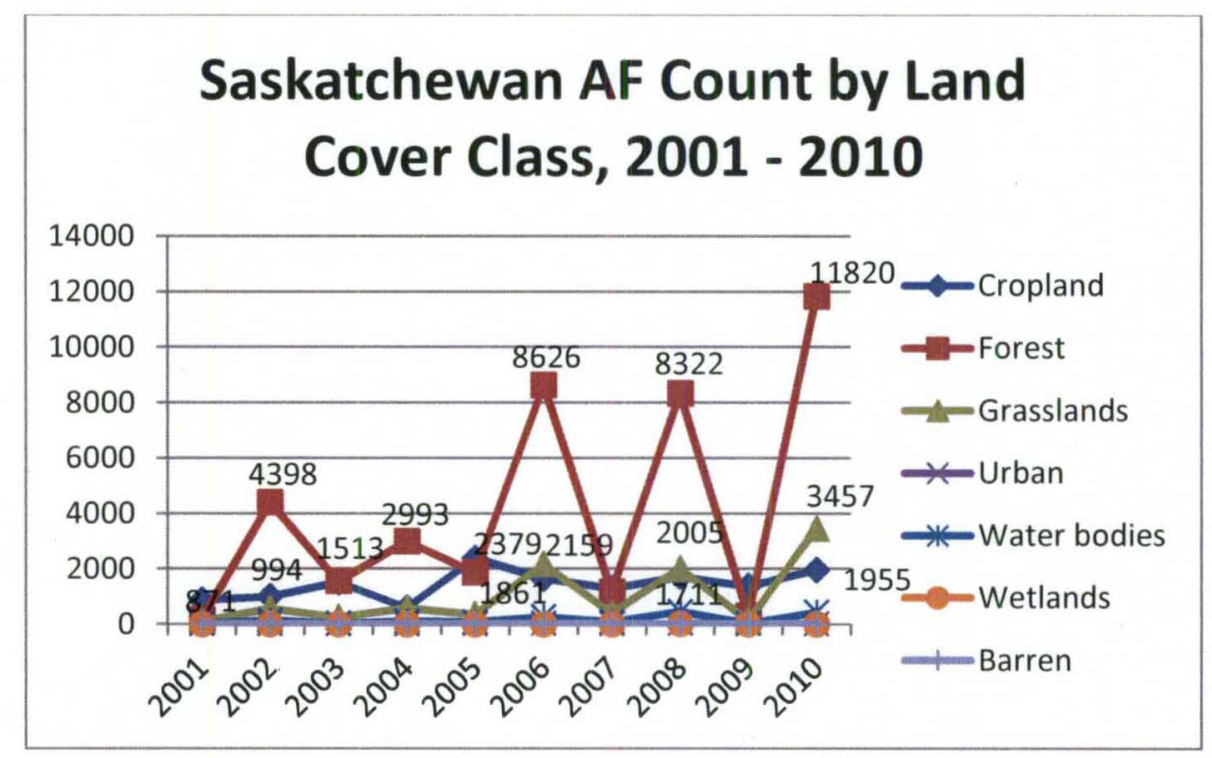

Figure 22. Number of AF detections by land cover class for Saskatchewan from 2001 to 2010 . 


\begin{tabular}{|c|c|c|c|c|c|c|c|c|c|c|c|}
\hline Saskatchewan & '01 & $\underline{02}$ & $\underline{03}$ & (04 & 65 & “06 & 67 & '08 & $\underline{69}$ & '10 & Total \\
\hline Cropland & 871 & 994 & 1513 & 581 & 2379 & 1644 & 1295 & 1711 & 1368 & 1955 & 14311 \\
\hline Forest & 162 & 4398 & 1545 & 2993 & 1861 & 8626 & 1166 & 8322 & 298 & 11820 & 41191 \\
\hline Grasslands & 97 & 551 & 242 & 565 & 342 & 2159 & 394 & 2005 & 119 & 3457 & 9931 \\
\hline Urban & 16 & 12 & 14 & 8 & 12 & 28 & 11 & 23 & 13 & 5 & 142 \\
\hline Water & 12 & 138 & 24 & 106 & 74 & 262 & 78 & 446 & 13 & 427 & 1580 \\
\hline Wetlands & 0 & 0 & 0 & 1 & 0 & 2 & 0 & 6 & 0 & 0 & 9 \\
\hline Barren & 3 & 3 & 2 & 0 & 5 & 19 & 1 & 9 & 3 & 1 & 46 \\
\hline Total & 1161 & 6096 & 3340 & 4254 & 4673 & 12740 & 2945 & 12522 & 1814 & 17665 & 67210 \\
\hline
\end{tabular}

Table 6. Raw number count of AF detections for Saskatchewan from 2001 to 2010.

Burned area data reveals a more complete picture of seasonal variations in distribution of fires across land cover classifications for Canada. Burned area data was available from 2003 to 2010 . For this study period of total of 74,909 BA pixels were classified by season and were detected for seven provinces.

\begin{tabular}{|l|c|c|c|c|c|c|c|c|c|}
\hline Canada & $\mathbf{2 0 0 3}$ & $\mathbf{2 0 0 4}$ & $\mathbf{2 0 0 5}$ & $\mathbf{2 0 0 6}$ & $\mathbf{2 0 0 7}$ & $\mathbf{2 0 0 8}$ & $\mathbf{2 0 0 9}$ & $\mathbf{2 0 1 0}$ & Total \\
\hline Spring (Jan-Mar) & 6 & 0 & 0 & 0 & 0 & 2 & 0 & 9 & 17 \\
\hline Summer (Apr-June) & 4,933 & 1,069 & 13,648 & 9,616 & 1,245 & 3,464 & 4,799 & 3,083 & 41,857 \\
\hline Fall (July-Sept) & 3,313 & 206 & 3,351 & 6,486 & 2,634 & 1,298 & 496 & 2,489 & 20,273 \\
\hline Winter (Oct-Dec) & 4,858 & 1,211 & 290 & 1,256 & 654 & 1,782 & 7 & 2,704 & 12,762 \\
\hline \multicolumn{1}{r|}{ Total: } & 13,110 & 2,486 & 17,289 & 17,358 & 4,533 & 6,546 & 5,302 & 8,285 & 74,909 \\
\hline
\end{tabular}

Table 7. Raw number count of BA detections for Canada from 2003 to 2010 by season. 
Summer months accounted for the largest percentage of Burned Area pixels detected for the whole of Canada from 2003 to 2010. Summer accounted for $55.9 \%$ of total BA detections in Canada for the study period. Fall accounted for $27.1 \%$ of the BA detections while winter accounted for $17.0 \%$. Spring accounted for less than $0.1 \%$ of the total BA detections in Canada from 2003 to 2010. The peak season for BA detection in Canada was the summer of 2005 (13,648 detections) followed by the summer of 2006 (9,616 detections) and fall 2006 (6,486 detections). The summer of 2005 accounted for $18.2 \%$ of the total BA detections in Canada from 2003 to 2010 . The summer of 2006 accounted for $12.8 \%$ of the total BA detections in Canada from 2003 to 2010 . The fall of 2005 accounted for $8.65 \%$ of the total BA detections in Canada from 2003 to 2010.

Forest fire season reaches its peak during the hottest months when fuel loads increase due to dry, combustible prone conditions. Brush clearing and crop residuals are also cleared and burned towards the end of the harvest season in order to prepare fields for the winter and certainly play a role in the larger number of BA detections in the Summer and Fall Seasons. Winter burned area detections can be misleading in the Northern Latitudes and field research was used to uncover what was occurring in the region from October to December. The results of the field research are discussed in the concluding section; however, it can be briefly noted that carbon rich soil and land cover conversion are significant players in pinging BA detections in Canadian provinces in winter and early springtime. 


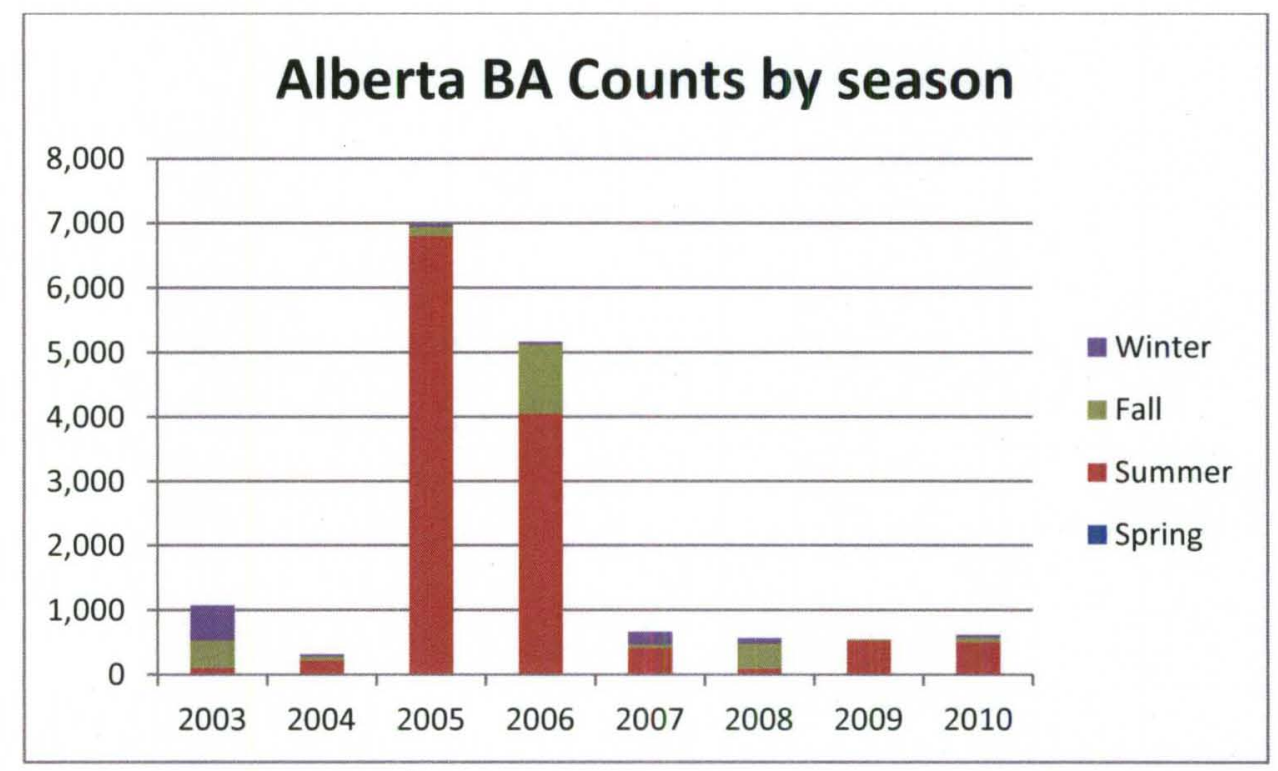

Figure 23. Seasonal BA detections from 2003 to 2010 in Alberta.

\begin{tabular}{|l|l|l|l|l|l|l|l|l|l|}
\hline Alberta & $\mathbf{0 3}$ & $\mathbf{0 4}$ & $\mathbf{6 0 5}$ & $\mathbf{6} \mathbf{0 6}$ & $\mathbf{6} \mathbf{0 7}$ & $\mathbf{6} \mathbf{0 8}$ & $\mathbf{6} \mathbf{0 9}$ & $\mathbf{'} \mathbf{1 0}$ & Total \\
\hline Spring (Jan-Mar) & 0 & 0 & 0 & 0 & 0 & 1 & 0 & 1 & 2 \\
\hline Summer (Apr-June) & 104 & 218 & 6,801 & 4,054 & 413 & 88 & 530 & 501 & 12,709 \\
\hline Fall (July-Sept) & 429 & 63 & 136 & 1,068 & 50 & 392 & 12 & 75 & 2,225 \\
\hline Winter (Oct-Dec) & 539 & 32 & 50 & 37 & 195 & 83 & 0 & 40 & 976 \\
\hline & 1,072 & 313 & 6,987 & 5,159 & 658 & 564 & 542 & 617 & 15,912 \\
\hline
\end{tabular}

Table 8. Raw number count of BA detections for Alberta from 2003 to 2010 by season.

There were 15,912 total BA detections from 2003 to 2010 in Alberta. Alberta accounted for $21.2 \%$ of the total BA detection in Canada for the study period. The peak BA detections in Alberta occurred in summer 2005 (6,801 detections) and 2006 (4,054 detections) and the fall of 2006 (1,068 detections). Summer 2005 accounted for $42.7 \%$ of 
the BA detections in Alberta from 2003 to 2010; summer 2005 accounted for $25.5 \%$, and fall 2006 accounted for $6.7 \%$.

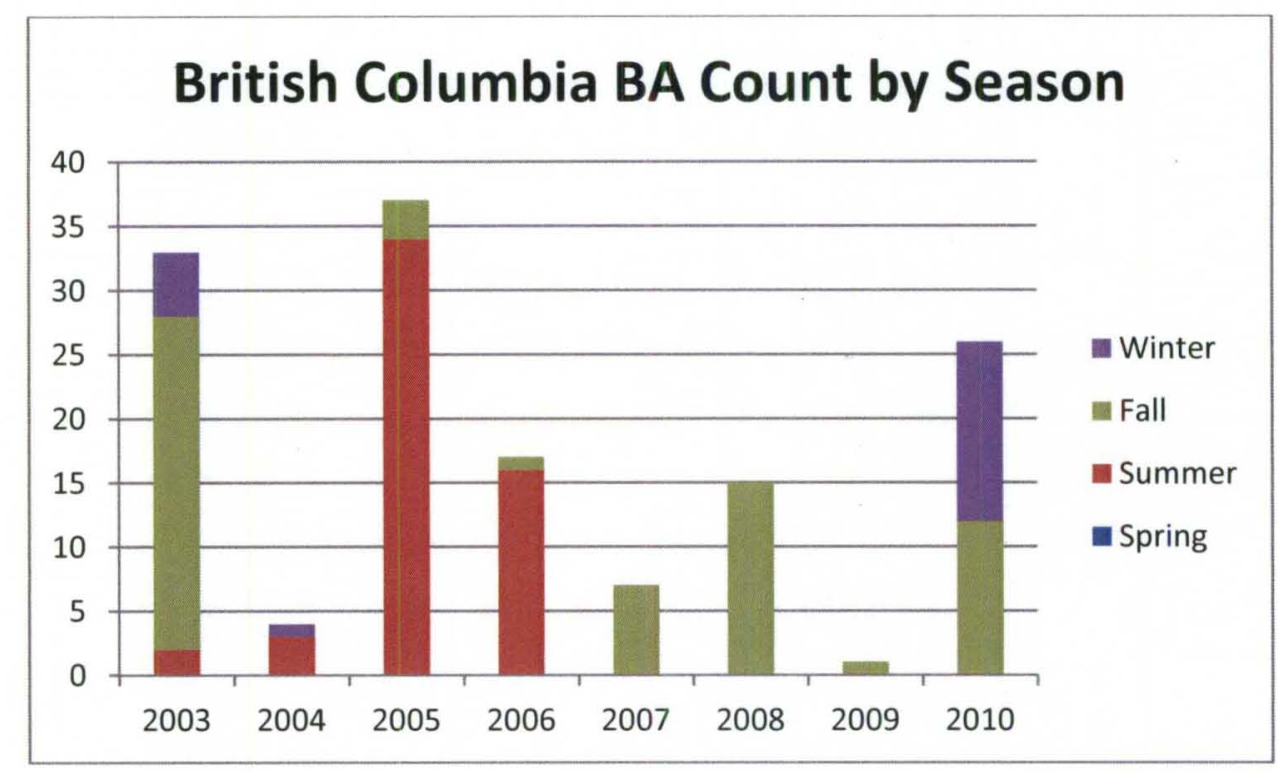

Figure 24. Seasonal BA detections from 2003 to 2010 in British Columbia.

\begin{tabular}{|l|c|c|c|c|c|c|c|c|c|}
\hline British Columbia & $\underline{\mathbf{0 3}}$ & $\underline{\mathbf{0 4}}$ & $\underline{\mathbf{0 5}}$ & $\underline{\mathbf{6 0 6}}$ & $\underline{\mathbf{0 7}}$ & $\underline{\mathbf{0 8}}$ & $\underline{\mathbf{0 9}}$ & $\underline{\mathbf{1 0}}$ & $\underline{\mathbf{T o t a l}}$ \\
\hline Spring (Jan-mar) & 0 & 0 & 0 & 0 & 0 & 0 & 0 & 0 & 0 \\
\hline Summer (Apr-June) & 2 & 3 & 34 & 16 & 0 & 0 & 0 & 0 & 55 \\
\hline Fall (July-Sept) & 26 & 0 & 3 & 1 & 7 & 15 & 1 & 12 & 65 \\
\hline Winter (Oct-Dec) & 5 & 1 & 0 & 0 & 0 & 0 & 0 & 14 & 20 \\
\hline & 33 & 4 & 37 & 17 & 7 & 15 & 1 & 26 & 140 \\
\hline
\end{tabular}

Table 9. Raw number count of BA detections for British Columbia from 2003 to 2010 by season.

There were 140 total BA detections from 2003 to 2010 in British Columbia.

British Columbia accounted for less than $1 \%$ of the total BA detection in Canada for the 
study period. The peak BA detections in British Columbia occurred in summer 2005 (34 detections) and fall 2006 (26 detections). Summer 2005 accounted for $24.3 \%$ of the BA detections in British Columbia from 2003 to 2010 . Fall 2006 accounted for $16.4 \%$.

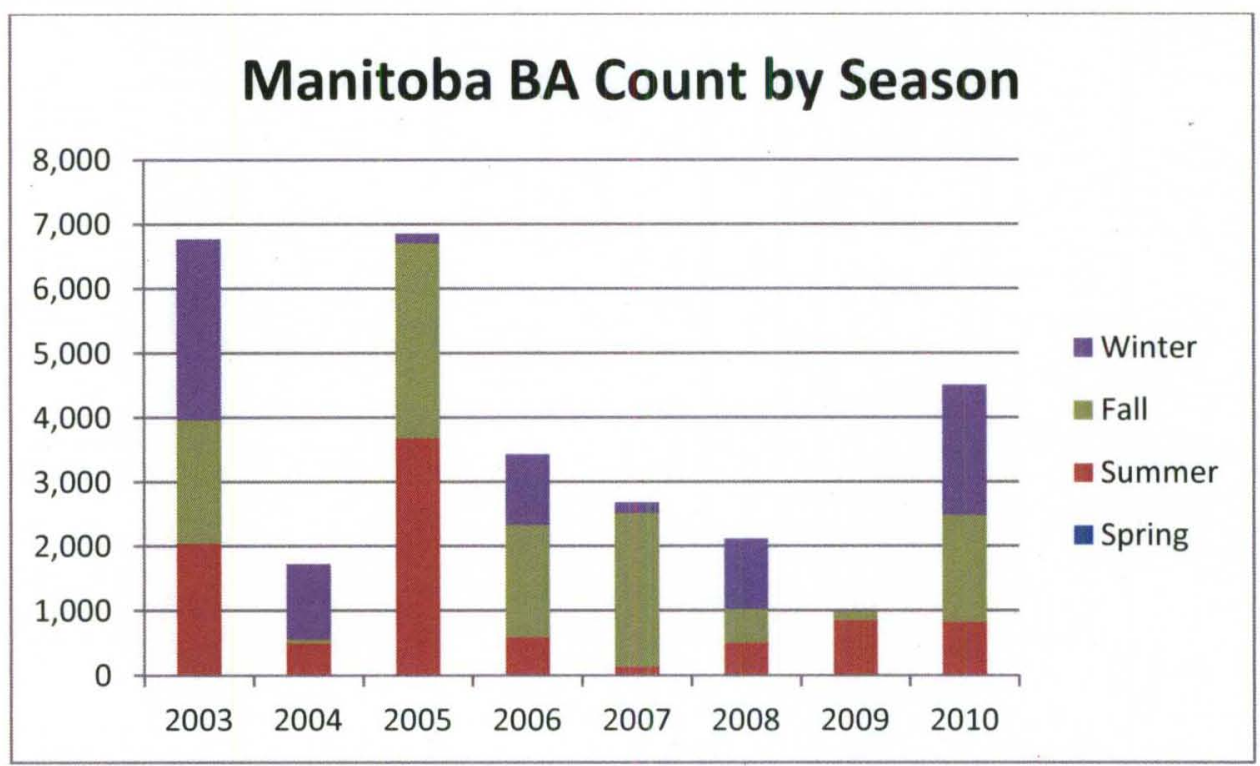

Figure 25. Seasonal BA detections from 2003 to 2010 in Manitoba.

\begin{tabular}{|c|c|c|c|c|c|c|c|c|c|}
\hline Manitoba & $\mathbf{0 3}$ & $\mathbf{6 0 4}$ & $\mathbf{6 0 5}$ & $\mathbf{6} \mathbf{0 6}$ & $\mathbf{6} \mathbf{0 7}$ & $\mathbf{6 0 8}$ & $\mathbf{6} \mathbf{0 9}$ & $\mathbf{'} \mathbf{1 0}$ & Total \\
\hline Spring (Jan-mar) & 6 & 0 & 0 & 0 & 0 & 0 & 0 & 8 & 14 \\
\hline Summer (Apr-June) & 2,038 & 496 & 3,683 & 593 & 138 & 503 & 855 & 819 & 9,125 \\
\hline Fall (July-Sept) & 1,914 & 59 & 3,019 & 1,734 & 2,378 & 518 & 121 & 1,658 & 11,401 \\
\hline Winter (Oct-Dec) & 2,808 & 1,160 & 146 & 1,098 & 161 & 1,087 & 0 & 2,016 & 8,476 \\
\hline & 6,766 & 1,715 & 6,848 & 3,425 & 2,677 & 2,108 & 976 & 4,501 & 29,016 \\
\hline
\end{tabular}

Table 10. Raw number count of BA detections for Manitoba from 2003 to 2010 by season.

There were 29,016 total BA detections from 2003 to 2010 in Manitoba. Manitoba accounted for $38.7 \%$ of the total BA detection in Canada for the study period. The peak 
BA detections in Manitoba occurred in summer 2005 (3,683 detections), fall 2005 (3,019 detections), and winter 2003 (2,808 detections). Summer 2005 accounted for $12.7 \%$ of the BA detections in Manitoba from 2003 to 2010; fall 2005 accounted for 10.4\%, and winter 2003 accounted for $9.7 \%$.

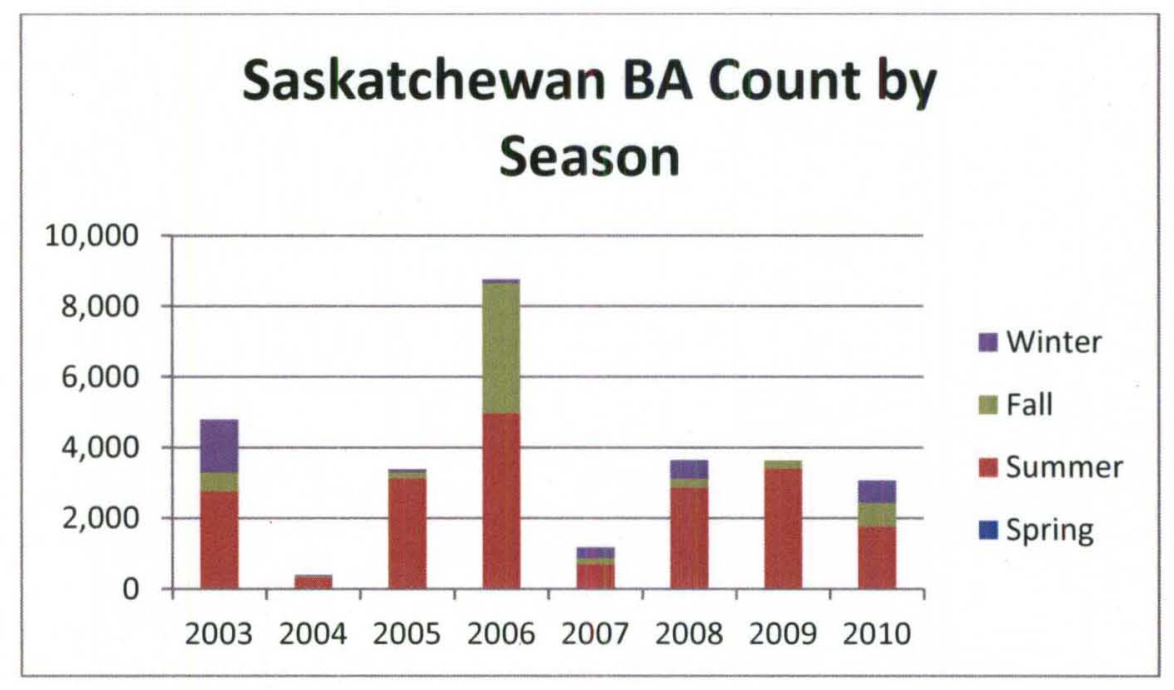

Figure 26. Seasonal BA detections from 2003 to 2010 in Saskatchewan.

\begin{tabular}{|l|l|l|l|l|l|l|l|l|l|}
\hline Saskatchewan & $\mathbf{0 3}$ & $\mathbf{6} \mathbf{0 4}$ & $\mathbf{6 0 5}$ & $\mathbf{6} \mathbf{0 6}$ & $\mathbf{6} \mathbf{0 7}$ & $\mathbf{6 0}$ & $\mathbf{6 0 9}$ & $\mathbf{1 0}$ & Total \\
\hline Spring (Jan-mar) & 0 & 0 & 0 & 0 & 0 & 1 & 0 & 0 & 1 \\
\hline Summer (Apr-June) & 2,765 & 334 & 3,124 & 4,972 & 690 & 2,866 & 3,395 & 1,758 & 19,904 \\
\hline Fall (July-Sept) & 527 & 35 & 161 & 3,670 & 185 & 246 & 229 & 674 & 5,727 \\
\hline Winter (Oct-Dec) & 1,486 & 17 & 92 & 114 & 289 & 515 & 0 & 626 & 3,139 \\
\hline & 4,778 & 386 & 3,377 & 8,756 & 1,164 & 3,628 & 3,624 & 3,058 & 28,771 \\
\hline
\end{tabular}

Table 11. Raw number count of BA detections for Saskatchewan from 2003 to 2010 by season.

There were 28,771 total BA detections from 2003 to 2010 in Saskatchewan. Saskatchewan accounted for $38.4 \%$ of the total BA detection in Canada for the study 
period. The peak BA detections in Saskatchewan occurred in summer $2006(4,972$

detections), fall 2006 (3,670 detections), and summer 2009 (3,395 detections). Summer 2006 accounted for $17.3 \%$ of the BA detections in Saskatchewan from 2003 to 2010; fall 2006 accounted for $12.8 \%$, and fall 2006 accounted for $11.8 \%$.

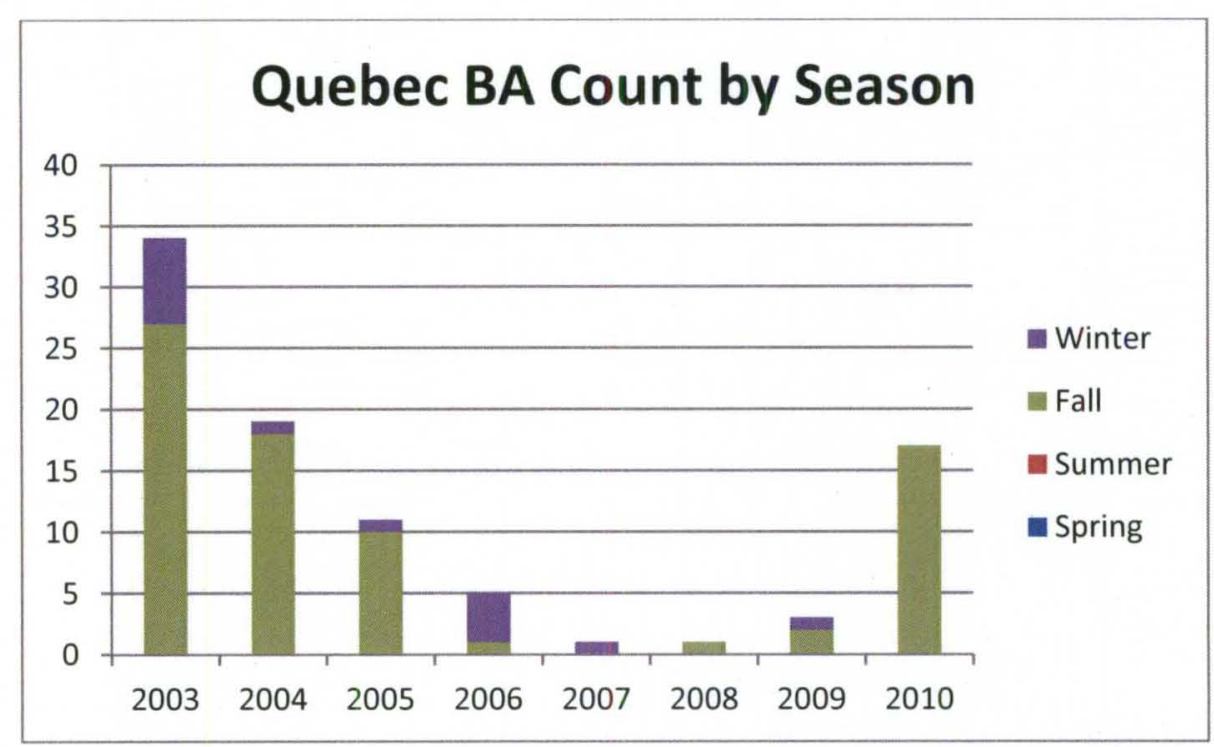

Figure 27. Seasonal BA detections from 2003 to 2010 in Quebec.

\begin{tabular}{|l|c|c|c|c|c|c|c|c|c|}
\hline Quebec & $\mathbf{0 3}$ & $\mathbf{6 4}$ & $\mathbf{6 5}$ & $\mathbf{6 0 6}$ & $\mathbf{6} \mathbf{0 7}$ & $\mathbf{6 8}$ & $\mathbf{0 9}$ & $\mathbf{1 0}$ & Total \\
\hline Spring (Jan-mar) & 0 & 0 & 0 & 0 & 0 & 0 & 0 & 0 & 0 \\
\hline Summer (Apr-June) & 0 & 0 & 0 & 0 & 0 & 0 & 0 & 0 & 0 \\
\hline Fall (July-Sept) & 27 & 18 & 10 & 1 & 0 & 1 & 2 & 17 & 76 \\
\hline Winter (Oct-Dec) & 7 & 1 & 1 & 4 & 1 & 0 & 1 & 0 & 15 \\
\hline & 34 & 19 & 11 & 5 & 1 & 1 & 3 & 17 & 91 \\
\hline
\end{tabular}

Table 12. Raw number count of BA detections for Quebec from 2003 to 2010 by season. 
There were 91 total BA detections from 2003 to 2010 in Quebec. Quebec accounted for less than $1 \%$ of the total BA detection in Canada for the study period. The peak BA detections in Quebec occurred in fall 2003 and fall 2004. There were 27 BA detections in fall 2003 accounting for $29.7 \%$ of the BA detections in Quebec from 2003 to 2010 . The 18 BA detections in fall 2004 accounted for $19.8 \%$.

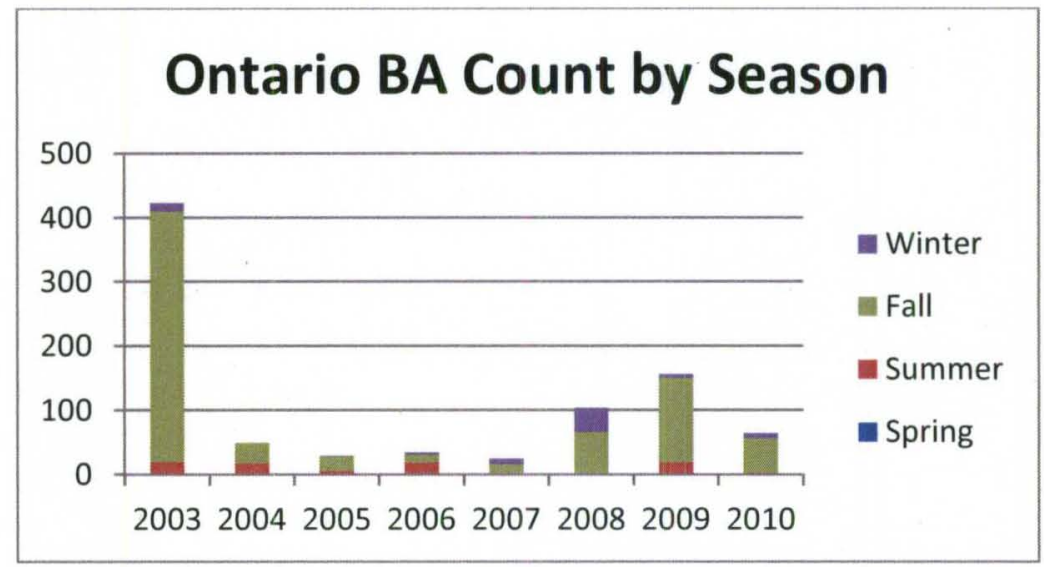

Figure 28. Graph of seasonal BA detections from 2003 to 2010 in Ontario.

\begin{tabular}{|l|c|c|c|c|c|c|c|c|c|}
\hline Ontario & $\mathbf{0 3}$ & $\mathbf{6 0 4}$ & $\mathbf{6 5}$ & $\mathbf{6} \mathbf{0 6}$ & $\mathbf{6} \mathbf{0 7}$ & $\mathbf{6} \mathbf{0 8}$ & $\mathbf{6} \mathbf{0 9}$ & $\mathbf{'} \mathbf{1 0}$ & Total \\
\hline Spring (Jan-mar) & 0 & 0 & 0 & 0 & 0 & 0 & 0 & 0 & 0 \\
\hline Summer (Apr-June) & 20 & 18 & 6 & 19 & 2 & 0 & 19 & 3 & 87 \\
\hline Fall (July-Sept) & 390 & 31 & 22 & 12 & 14 & 66 & 131 & 53 & 719 \\
\hline Winter (Oct-Dec) & 13 & 0 & 1 & 3 & 8 & 37 & 6 & 8 & 76 \\
\hline & 423 & 49 & 29 & 34 & 24 & 103 & 156 & 64 & 882 \\
\hline
\end{tabular}

Table 13. Raw number count of BA detections for Ontario from 2003 to 2010 by season.

There were 882 total BA detections from 2003 to 2010 in Ontario. Ontario accounted for $1.2 \%$ of the total BA detection in Canada for the study period. The peak 
BA detections in Ontario occurred in fall 2003 (390 detections) and fall 2009 (131

detections). Fall 2003 accounted for $44.2 \%$ of the BA detections in Ontario from 2003 to 2010; fall 2009 accounted for $14.9 \%$.

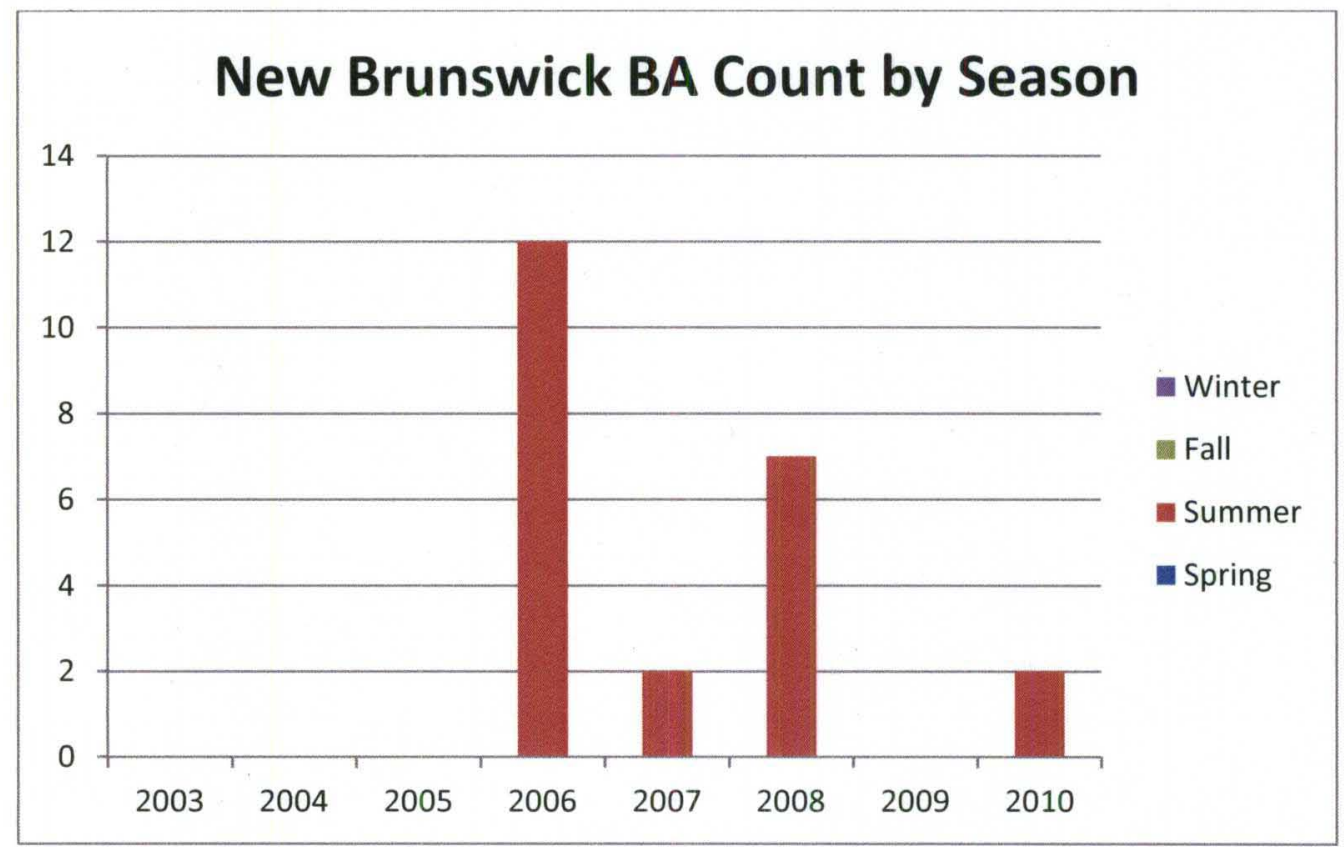

Figure 29. Seasonal BA detections from 2003 to 2010 in New Brunswick.

\begin{tabular}{|l|l|l|l|l|l|l|l|l|l|}
\hline New Brunswick & $\mathbf{6 3}$ & $\mathbf{6 4}$ & $\mathbf{6 5}$ & $\mathbf{6 0 6}$ & $\mathbf{6 0 7}$ & $\mathbf{6 0}$ & $\mathbf{6 9}$ & $\mathbf{'} \mathbf{1 0}$ & Total \\
\hline Spring (Jan-mar) & 0 & 0 & 0 & 0 & 0 & 0 & 0 & 0 & 0 \\
\hline Summer (Apr-June) & 0 & 0 & 0 & 12 & 2 & 7 & 0 & 2 & 23 \\
\hline Fall (July-Sept) & 0 & 0 & 0 & 0 & 0 & 0 & 0 & 0 & 0 \\
\hline Winter (Oct-Dec) & 0 & 0 & 0 & 0 & 0 & 0 & 0 & 0 & 0 \\
\hline & 0 & 0 & 0 & 12 & 2 & 7 & 0 & 2 & 23 \\
\hline
\end{tabular}

Table 14. Raw number count of BA detections for New Brunswick from 2003 to 2010 by season. 
There were 23 total BA detections from 2003 to 2010 in New Brunswick. New Brunswick accounted for less than $1 \%$ of the total BA detection in Canada for the study period. The peak BA detections in New Brunswick occurred in summer 2006. Summer 2006 accounted for $52.2 \%$ of the BA detections in New Brunswick from 2003 to 2010. 


\section{Peace River Agricultural Area (PRAA) Field Work}

The most northern agricultural region in North America is the PRAA, which straddles the border of Northeastern British Columbia and Northwestern Alberta (Figure 30).

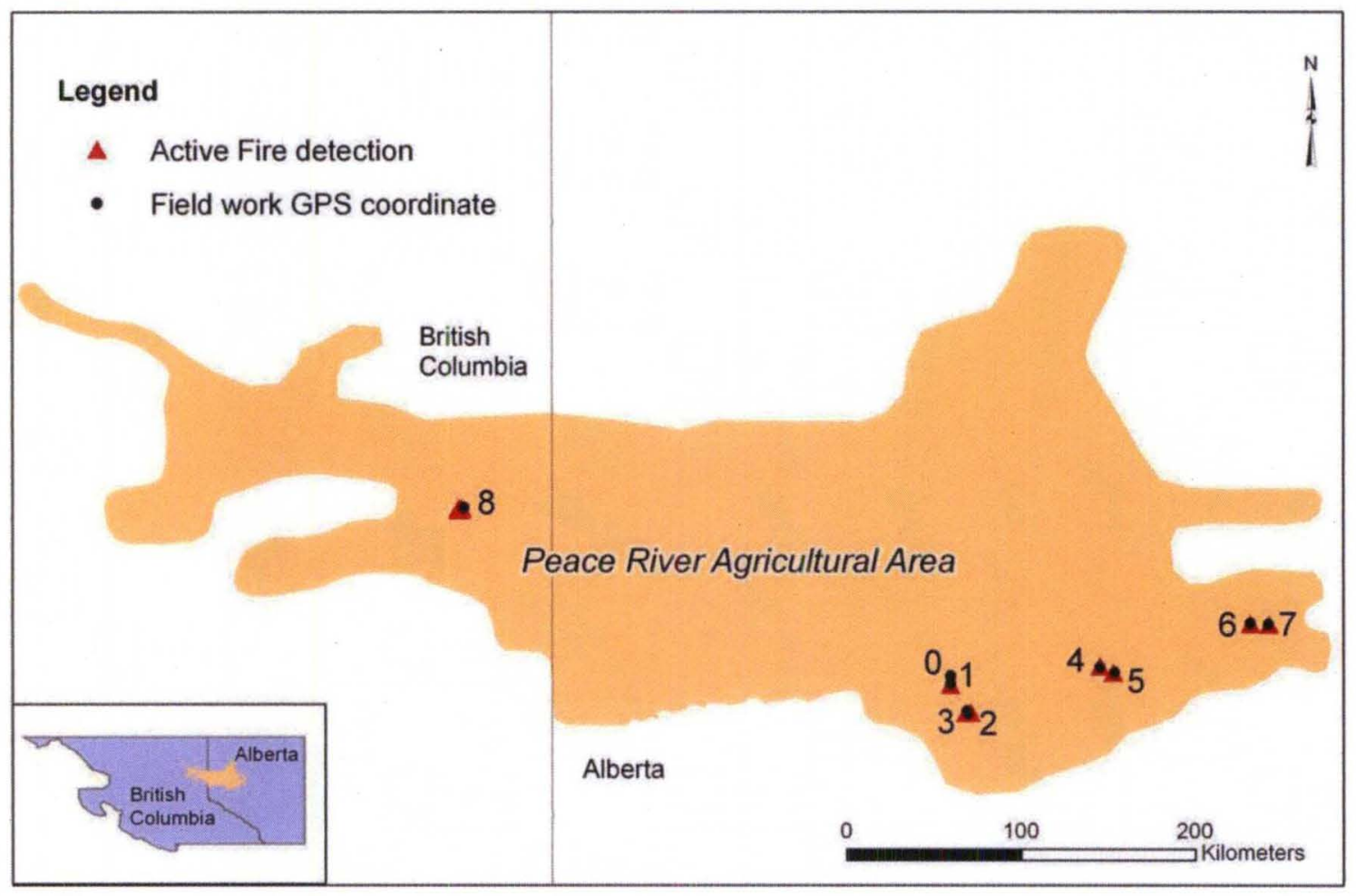

Figure 30. Location of field work GPS points collected and MODIS active fire detections in the Peace River agricultural area.

The British Columbia portion produces $77 \%$ of the provinces' grains and the Alberta side grows canola, wheat and hay (British Columbia agriculture in the classroom foundation 2008; Agriculture and Agri-Food Canada 2000). Field work was conducted April 9-10th of 2011 on active fire points from the previous 6 months (October 2010 - 
March 2011) that were supposedly located in croplands. The goal was to determine if any of the fires had been the result of crop residue burning, a practice commonly used to clear fields after harvest. Hegg et al. (2010) identified the region as being a source of black carbon in the Arctic due to cropland and grassland spring burning. The transport of aerosols from mid-latitudes to the Arctic is favored during the spring and has the most impact on snow melt.

The results of the field work showed that crop residue was not being burned during early April, nor was there evidence of fall burning. We found numerous large piles of trees and underbrush at all but one active fire point location. This indicated to us that the source of fire was from clearing the land and/or land conversion to maintain or expand agricultural fields (Figures $31-32 a-f)$.
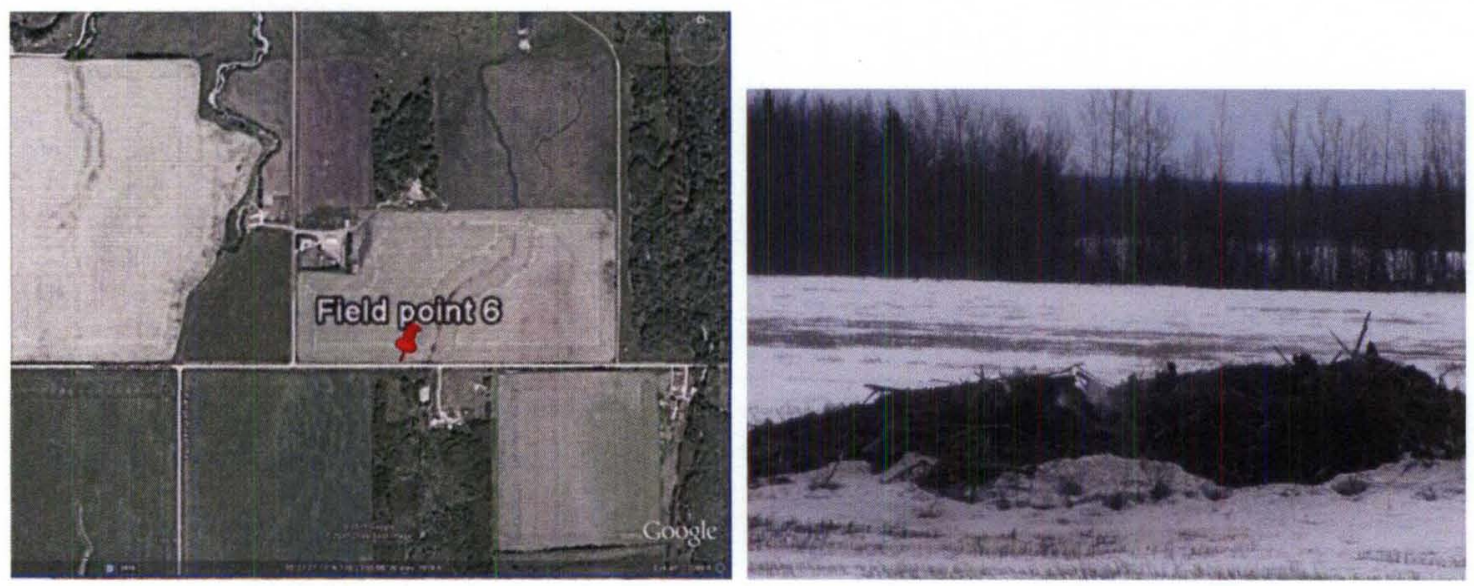

Figure 31. Picture taken at active fire location (field point number 6 in Figure 30 on page 46) with side comparison of field in Google Earth. 


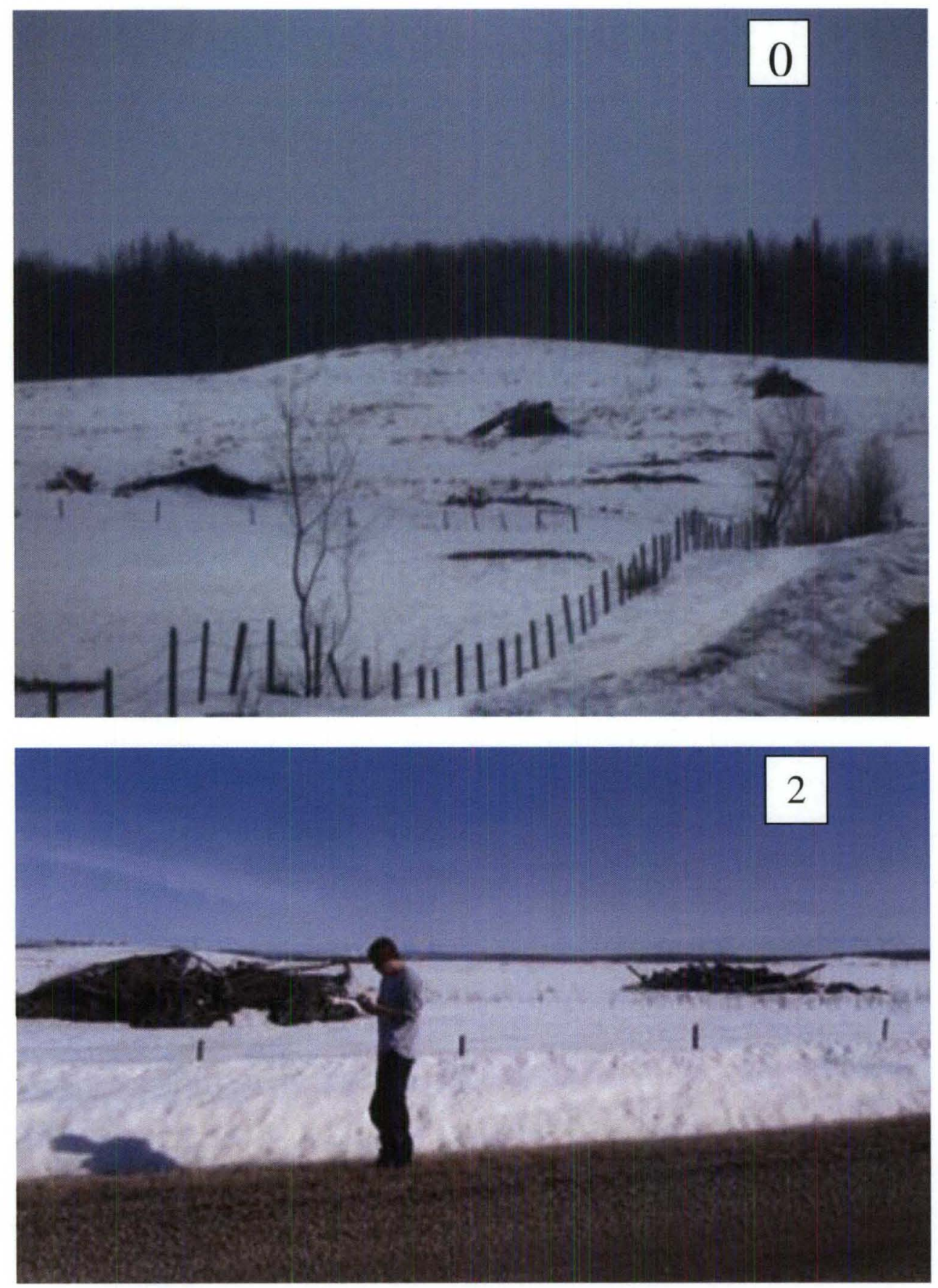

Figure 32a-b. Field points 0 and 2 as depicted in Figure 30 (page 46). 

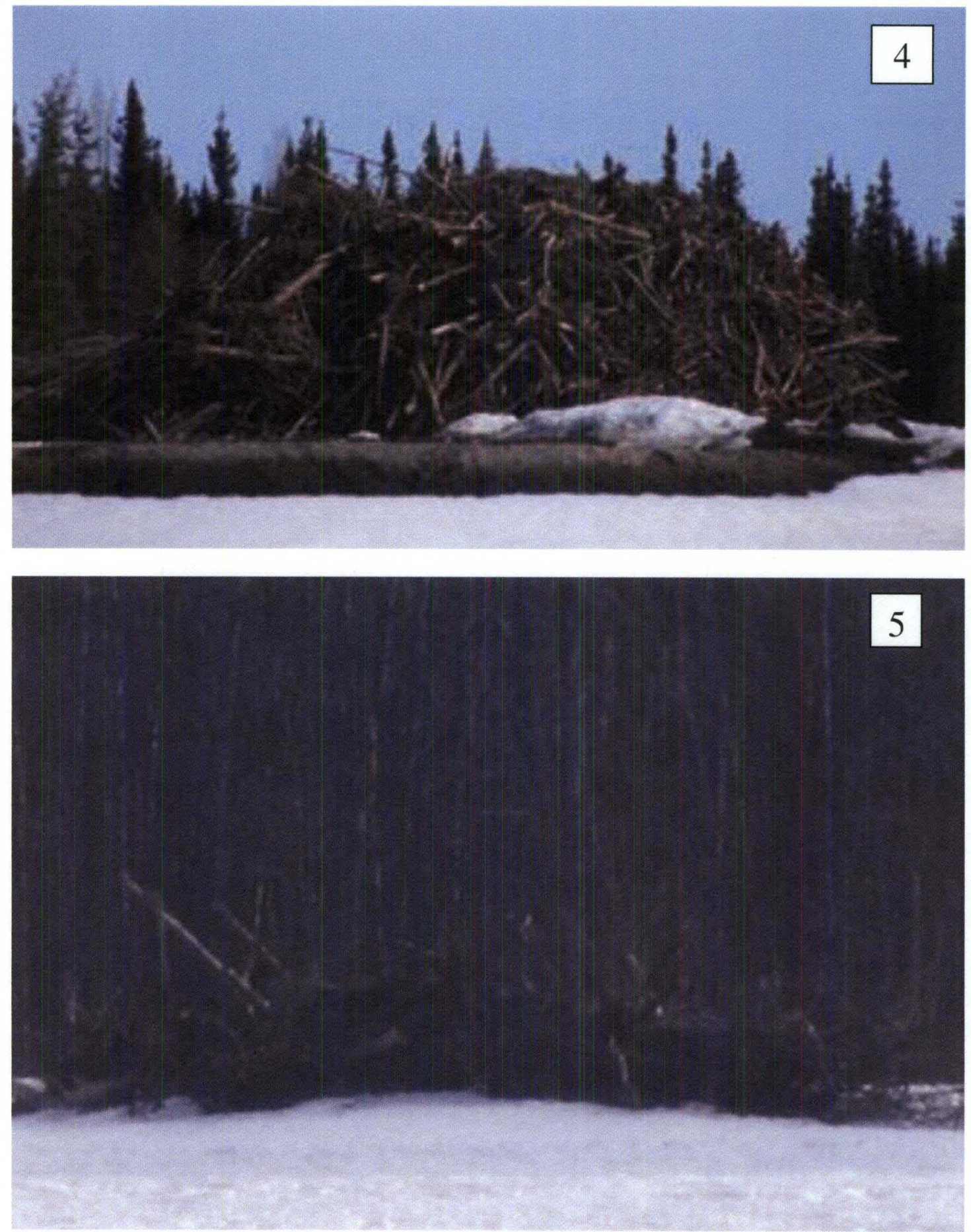

Figure 32c-d. Field points 4 and 5 as depicted in Figure 30 (page 46). 


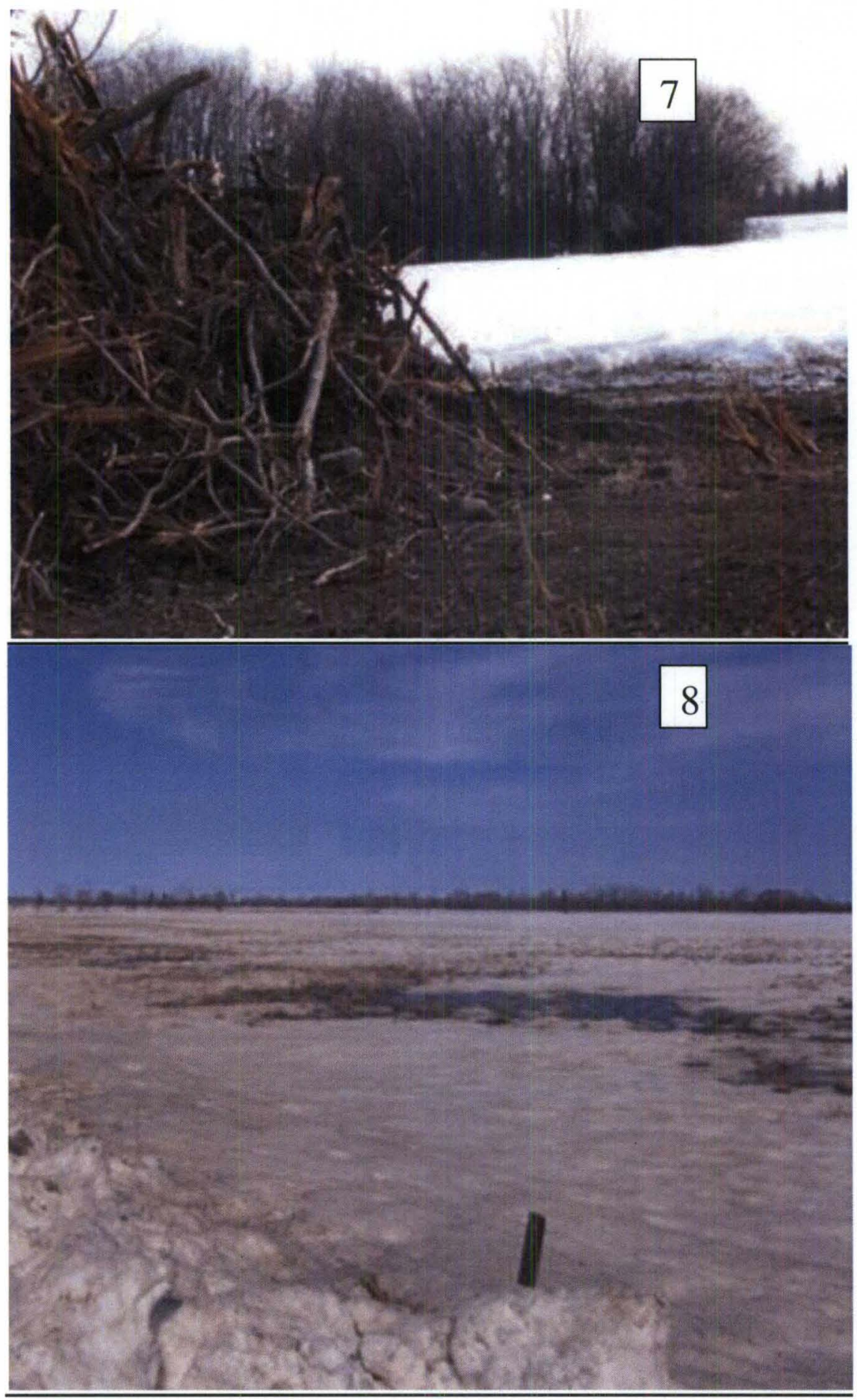

Figure 32e-f. Field points 7 and 8 as depicted in Figure 30 (page 46). 


\section{CONCLUSION}

Final conclusions from field work in the PRAA revealed several important conclusions about vegetation burning. Investigation of the Peace River agricultural area found active land use conversion from forest/shrubland to cropland/pasture. What seemed to be occurring in many instances was over the course of late fall, winter, and early spring farmers began to clear away to in-creeping brush and tree lines around the edges of their fields to maintain field lines or to expand the area of the field. Brush, thick weeds, and timbered trees were then stacked into large piles, some as tall as 3 meters or more and often lined out in even spread, grid like patterns across the field.

Talking to locals revealed that this was done for two main reasons. First, it prevented one large fire from having to be maintained. One large fire poses a threat to the soil and could spread to nearby forests if not managed properly. Fires of such large size can often draw unwanted attention from authorities; a positive for farmers, however, it undermines the ability to regulate emissions. The second reason was that the spread pattern of the burn piles helps to clear off snow cover when burned in the later spring time. Farm machinery can then more easily spread the charred residue over a larger area of the field for nutrient supplementation of the soil. There was, however, little evidence of fall and early spring field burning maintenance, suggesting that these piles were collected through the fall, winter, and early spring and burned sometime in late April or early May. 
The large amount of prairie province cropland burning in the spring may contribute to black carbon deposition in the Arctic. Because the material was often shrub or forest material located in a field, some confusion can be created as to what is the source of the emissions. Forest material in Canada often grows in an alfisol, or iron and aluminum rich soil. Tracer alfisols detected in BC deposits suggest that forest fires are the source of major BC deposits in the Arctic. However field research in the PRAA revealed that the wooded/shrubby material was being cleared and burnt in fields and were not sourced from wide, forested areas as Hegg et al. 2010 had suggested. Field research also showed that the black, carbon rich soil, still mostly covered in mid April, could be pinging BA detections in the MODIS sensor for winter months. When snow melts off in patches and reveals the dark soil it has a strikingly similar appearance to burned area after a fire. Further field work and collaborative processing with the MODIS team could help to rectify the potential signal confusion in late winter for Northern latitudes.

Forest, grassland, and cropland are the dominant land cover types where active fires were detected from 2001 to 2010 . Forest and grassland share a similar fire pattern over all of the years while cropland is distinct and has less inter-annual variability of fire activity. Cropland fires peak in the spring while forest and shrubland peak in the summer months and into the fall. Saskatchewan is the leading source of cropland active fires and burned area, followed by Manitoba and Alberta. British Columbia and Saskatchewan are the primary sources of forest fire detections.

Using the MODIS sensor it is possible to classify and quantify the location and source of fires in Canada. When coupled with field research we are able to complete a 
more accurate picture of burning and fire emissions in Canada. This project can serve as a stepping stone for future research into quantifying the particular "greenhouse" gasses and $\mathrm{BC}$ deposition responsible for driving up temperatures in micro-climate regions of Canada as well as decreasing the albedo of the Arctic surface.

This study is also important as it can aid fire management and medical response teams in planning for emergency events. By reviewing the locations, times, and types of fires they will be dealing with fire emergency units will be better prepared to handle fires when they occur. British Columbia's fires occur almost exclusively in forested areas. As such specific training and protocols need to be followed in comparison to standards used in urban house fires or agricultural burns in farmland. Locating sources of water nearby the most fire prone areas with clear access for helicopter units can drastically reduce the time spent fighting forest fires. It can also aid in creating evacuation plans for at-risk communities susceptible to forest fire encroachment. Saskatchewan and Manitoba, however, experience the majority of agricultural fires. Local prescribed burn days and fire management and enforcement of cropland fires can aided by this research and the satellite data in that it reduces the in-the-field necessity to spot fires. Once fires are detected with the MODIS sensor a fire management specialist can be sent out to investigate the fire occurrence, greatly increasing the financial and human resources of the fire management office. 


\section{REFERENCE LIST}

Agriculture and Agri-Food Canada. 2000. Bi-weekly Bulletin: Alberta. Market Analysis Division, Winnipeg, Manitoba, 13: 2.

Boschetti, L., Roy, D., Justice, C., and Ju, J. 2009. MODIS collection 5 Burned Area Product - MCD45; user's guide version 2.0, November 2009: i - 30. Available at: http://modisfire.umd.edu/Documents/MODIS_Burned_Area_User_Guide_2.0.pdf. Last access: January 21, 2012

Eamer, C., 2004. Yukon wildfire season hottest in Canada. Your Yukon. Column 381, series I. < http://www.taiga.net/yourYukon/col381.html> last visited March 8, 2012.

French, N., Kasischke, E., Hall, R., Murphy, K., Verbyl, D., Hoy, E., and Allen, J., 2008. Using Landsat data to assess fire and burn severity in the North American boreal forest region: an overview and summary of results. International Journal of Wildland Fire, 17, 443-457.

Friedl, M.A. McIver, D.K., Hodges, J., Zhang, X., Muchoney, D., Strahler, A., Woodcock, C., Gopal, S., Schneider, A., Cooper, A., Baccini, A., Gao, F., and Schaaf, C. 2002 Global land cover mapping from MODIS: algorithms and early results. Remote Sensing of Environment. 287-302.

Giglio, L. Descloitres, J., Justice, C., and Kaufman, Y. 2003. An enhanced contextual fire detection algorithm for MODIS. Remote Sensing of Environment, 87: 273-282.

Giglio, L. van der Werf, G., Randerson, J., Collatz, G., and Kasibhatla, P. 2005. Global estimation of burned area using MODIS active fire observations. Atmospheric Chemistry and Physics Discussions, 5: 11091-11141.

Hegg, D.A. Warren, S., Grenfell, T., Doherty, S., and Clarke, A. 2010. Sources of lightabsorbing aerosol in arctic snow and their seasonal variation. Atmospheric Chemistry and Physics, 10: 10923-10938.

Justice, C.O., Roy, D., and Lewis, M. 2002. The MODIS fire products. Remote Sensing of Environment. 83: 244-262. 
Justice, C.O., Giglio, L., Boschetti, L., Roy, D., Csiszar, I., Morisette, J., and Kaufman, Y. 2006. MODIS fire products (version2.3, 1) (EOS ID\# 2741). Algorithm Technical Background Document: 1-34.

Korontzi, S., McCarty, J., Loboda, T., Kumar, S., and Justice, C., 2006. Global Distribution of agricultural fires in croplands from 3 years of moderate resolution Agricultural Fires and Arctic Climate Change 32 imaging Spectroradiometer (MODIS) data. Global Biogeochemical Cycles 20.

Kasischke, E. and Turetsky, M. 2006. Recent changes in the fire regime across the North American boreal region - spatial and temporal patterns of burning across Canada and Alaska. Geophysical Research Letters 33.

Kerr, T., Ernst, C., McCarty, J., and M. White, 2011. A Remote Sensing Analysis of Fire in British Columbia, Canada. Graduate Research Symposium Honorable Mention Student Poster Competition, April 2011.

Langmann, B, Duncan, B, Textor, C, Trentmann, J., and van der Werf, G.R., 2009. Vegetation fire emissions and their impact on air pollution and climate. Atmospheric

Environment 43, 107-116.

MODIS LAND COVER homepage: http://modis-land.gsfc.nasa.gov/landcover.htm

Mokwunye, U. 2000. Do African Soils only Sustain Subsistence Agriculture? Villages in the Future: Crops, Jobs, and Livelihoods. Springer Press. 175 -180.

NASA/University of Maryland. 2002. MODIS Hotspot / Active Fire Detections. Data set. MODIS Rapid Response Project, NASA/GSFC [producer], University of Maryland, Fire Information for Resource Management System [distributors]. Available on-line [http://maps.geog.umd.edu]

Soja, A. J., Al-Saadi, J, Giglio, L., Randall, D., Kittaka, C., Pouliot, G., Kordzi, J., Raffuse, S., Pace, T. G., Pierce, T. E., Moore, T., Roy, B., Pierce, R. B., and Szykman, J. J., 2009. Assessing satellite-based fire data for use in the National Emissions Inventory. Journal of Applied Remote Sensing. 3, 031504.

Soja, A. J., Tchebakova, N. M., French, N. H. F., Flannigan, M. D., Shugart, H. H., Stocks, B. J., Sukhinin, A. I., Parfenova, E. I., Chapin, F. S., Stackhouse, P. W., 2007 ,

Climate-induced boreal forest change: Predictions versus current observations. Global and Planetary Change 56. 274-296. 
Statistics Canada. 2011. Canada year book 2011; agriculture: catalogue no. 11-402-X: 20. Available at: http://www.statcan.gc.ca/pub/11-402-x/2011000/pdf/agricultureeng.pdf. Last access: December 5, 2011.

The British Columbia Agriculture in the Classroom Foundation. 2008. "Grow BC" a guide to BC's agriculture resources: the regions. Abbotsford, BC: $8-10$. Available at: http://www.aitc.ca/bc/uploads/growbc/5_regions.pdf. Last access: February 2, 2012.

Van der Werf, G. R., Randerson, J. T., Giglio, L., Collatz, G. J., Kaskibhatla, P. S., Arellano Jr., A. F., 2006. Interannual variability in global biomass burning emissions

from 1997 to 2004. Atmospheric Chemistry and. Physics. 6, 4323-3441. 


\section{CURRICULUM VITAE}

539 W Saint Catherine Street

Louisville, KY 40203
724-388-5821

tfkerr01@louisville.edu

\section{Tyler F. Kerr}

\section{Experience}

\section{December 2011 - Present Department of Geography} Part-Time Faculty (Graduate Teaching Instructor)

- Serve as instructor of an Online Distance Learning Course, Geosciences 200 (The Global Environment), at the University of Louisville.

- Provide assignments and information relevant to each week's review of a Chapter from the assigned textbook. Respond and interact with student's discussion posts and lead in creating critical analysis of the material.

- Administrative management including responding to emails, grading, and rectifying online technical problems while ensuring a safe, fun, and beneficial learning environment.

\section{August 2011 - Present, October 2009 - May 2010 Athletics Department, University of Louisville Academic Tutor for Student Athletes}

Meet with student athletes for weekly study sessions, reviews of material, homework assistance, and test preparation and review. I assisted them in learning course material, preparing for tests and quizzes, and reviewed their written or calculated coursework per NCAA Guidelines.

\section{August 2010 - August 2011}

\section{Graduate Research Assistant for Dr. Jessica McCarty}

Planned and conducted field research to ground truth the locations of Kentucky tobacco fields as identified by the U.S. Department of Agriculture's Cropland Data Layer (CDL). Training data was then created using collected GPS 
information and ArcGIS per contract requests from the Environmental Protection Agency (EPA).

Calculated high, average, and low emissions of selected greenhouse gases from agricultural fires for $2003-2008$ in the United States as collected by the MODIS Fire Product. Emissions factors were calculated by a group of professors and EPA scientists. The results were used to help in the expansion of the EPA's emissions inventory.

Produced maps displaying areas within the continental United States comparing the overlap of two Fire Detection Products derived from satellite sensed imagery. Detected burn areas were classified by land cover type to highlight cropland and rangeland burning in agricultural areas of the US. Maps have been presented and discussed in several conference calls with EPA scientists.

Created image catalogs detailing major agricultural burn sites for regions throughout the United States, Canada, and Russia (near Moscow)

Served as a lab instructor for GEOG 355: Introduction to Remote Sensing. Labs moderated were "Analyzing Radar Signatures," "Supervised Classifications of LandSat TM Imagery," and "Multi-temporal Change Detection."

Presented work analyzing agricultural fire detections in Canada for the past decade at the Fall 2011 AGU Conference.

\section{May 2005 - August 2005, May2006 - August 2006 Summer Safety Intern, PennDot District 10}

Verify and Coordinate the location of road maintenance crews throughout a five (5) county jurisdiction.

Plan daily trips to intersect road crews for safety inspections.

Performed a drive-through and walk-through safety inspection per PennDot specifications and OSHA regulations with each crew's foreman.

Produced written reports for each inspection

Conducted two to three inspections for each foreman in each county. There were approximately 60 foremen in total.

\section{Education}

May 2010: B.S. Geography (Human/Environmental Interaction) University of Louisville Louisville, KY 40292

Currently: Completing M.S. in Applied Geography at the University of Louisville, anticipated graduation: May 2012 
Presentations December 2011: American Geophysical Union National Conference: ""Reclassified Cropland Active Fire and Burned Area Detections by the MODIS $1 \mathrm{~km}$ Sensor in Canadian Provinces by land cover type, 2001 - 2010"

October 2011: EPA Community Modeling and Analysis Conference (contributor): "Development of a Crop Residue Burning Emissions Inventory: Preliminary CMAQ Results"

April 2011: University of Louisville Graduate Research Symposium Honorable Mention: "A Remote Sensing Analysis of Fire in British Columbia, CA" by Carie Ernst, Tyler Kerr, Jessica McCarty and Megan White

October 2010: Applied Geography Conference Undergraduate Research Poster Competition: "Spatial Correlation of Foreclosures and Crime: How Increasing Numbers of Foreclosed Homes have Affected Crime Distribution in Louisville, KY"

- Advanced experience with ArcGIS, Arc Catalog, and Geodatabase design and management, and Microsoft Office.

- Experience performing GIS analysis, queries, searches and data manipulation to meet project needs on time.

- Experience planning and conducting field research excursions in the US and Canada.

- Field experience collecting environmental data (GPS, land cover analysis) and ground-truthing satellite information/imagery.

- Professional and academic experience in accurate data collection and analysis.

- Excel working in an environment promoting active team work and effective communication across all levels of employment.

- Familiar knowledge with 29 OSHA 1910, 1926 Regulations.

- Management and responsibility for the growth of knowledge in individuals while promoting increased independence in learning via interdependent communication.

- Classroom management and administration 